\title{
Synthesis of Fluorodienes
}

\author{
James E. Fearn
}

Institute for Materials Research, National Bureau of Standards, Washington, D.C. 20234

(September 11, 1970)

In a comprehensive study of the cyclic, interintramolecular mechanism in diene polymerization, all of the completely fluorinated dienes from $C_{5}$ to $C_{8}$ have been prepared with a high degree of purity. Also prepared were 4-chloroperfluoro-1,6-heptadiene and perfluoro-1,11-dodecadiene, the latter inadvertently. The successful syntheses involved, in most cases, a telomerization which utilized, as the starting material, $\mathrm{I}_{2}, \mathrm{ICl}, \mathrm{CF}_{2} \mathrm{CFCl}$, or $\mathrm{CF}_{2} \mathrm{CF}_{2}$. From these telomers, not only the dienes but many new intermediate compounds were prepared; they were then purified and characterized. The chemistry of these compounds, especially that relating to their polymerization, is briefly discussed.

Key words: Cyclic inter-intramolecular mechanism; diene polymerization; fluorodienes; intermediates; polymerization; purity; synthesis; telomerization.

\section{Introduction}

Earlier reports from these laboratories have covered the synthesis and polymerization of 4-chloroperfluoro-1,6-heptadiene $[1]^{1}$ and the chemistry involved in the preparation and polymerization of perfluoro-1,4pentadiene [2,3]. These compounds were prepared according to the method of Park and Lacher [4]:

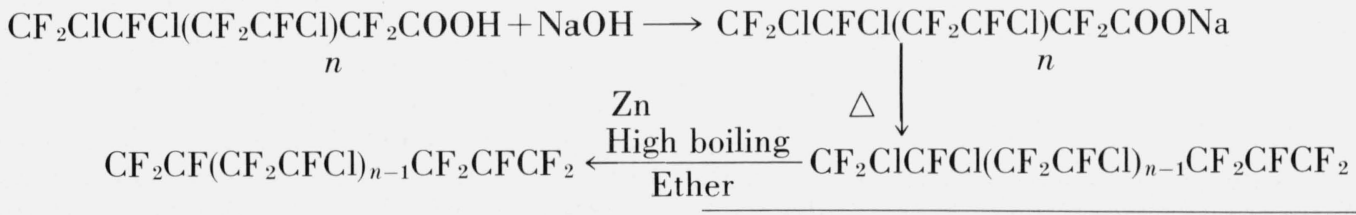

where $n$ is 2 in the starting telomer acid, the resulting diene is 4-chloroperfluoro-1,6-heptadiene, and the acid in which $n=1$ produced perfluoro-1,4-pentadiene. To a marked extent, each of these fluorodienes polym- erized according to an inter-intramolecular mechanism first postulated by Butler [5] after extensive investigations with allyl- and vinyl-amines and with quarternary ammonium salts. The general, idealized mechanism is:

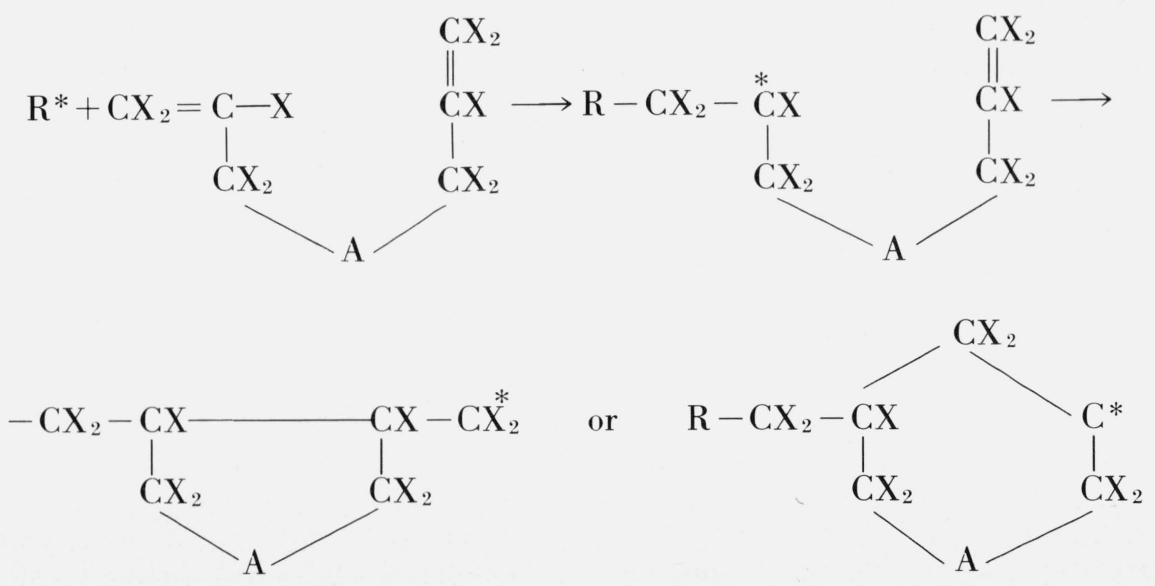

' Figures in brackets indicate the literature references at the end of this paper. 
where $\mathrm{X}=\mathrm{H}$ or $\mathrm{F}$, and $\mathrm{A}=\mathrm{CH}_{2}, \mathrm{CF}_{2}, \mathrm{~N}, \mathrm{NR}_{1} \mathrm{R}_{2}, \mathrm{~S}, \mathrm{R}_{2}$ $\mathrm{PH}$, or 0 . With hydrocarbon compounds, the sixmembered ring seems to be favored [5], but, with fluorocarbon compounds, this has not been established. A compound believed to have the structure $\mathrm{CF}_{2} \mathrm{BrCFCF}_{2} \mathrm{CFClCF}_{2} \mathrm{CFBrCF}_{2}$ could not be aromatized by passing it through a hot tube packed with $\mathrm{KF}$, although thermal defluorination reactions resulting in aromatization are known to occur. Nuclear magnetic resonance studies of the compound obtained in the telomerization reaction between 4-chloroperfluoroheptadiene and bromine suggest that it has a five-membered ring [6]. Polymers of 4-chloroperfluoro-1,6-heptadiene are tough, slightly flexible materials of high thermal stability. They may be cast, or pressed into clear transparent films having good optical properties.

Polymers of perfluoro-1,4-pentadiene formed at $\geqslant 10,000 \mathrm{~atm}$ have the general formula

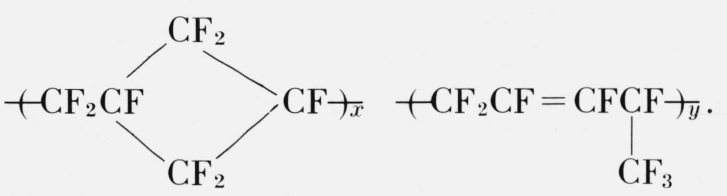

This structure is the result of the inward migration of one of the double bonds of the monomer, i.e., $\mathrm{CF}_{2}=\mathrm{CF}-\mathrm{CF}_{2}-\mathrm{CF}=\mathrm{CF}_{2} \rightleftarrows \mathrm{CF}_{2}=\mathrm{CF}-\mathrm{CF}$ $=\mathrm{CF}-\mathrm{CF}_{3}$. The resulting 1,3-pentadiene copolymerizes with the 1,4-pentadiene to give the structure shown. When $\frac{x+y}{y}$ is $\geqslant 20$, a powdery solid polymer of thermal stability is obtained, but when $\frac{x+y}{y}$ is $3-5$, the product is rubbery and considerably less stable. Infrared and nuclear magnetic resonance results tend to support this correlation between structure and properties [2]. Polymerization of perfluoro-1,4-pentadiene is further complicated by the formation of four isomeric dimers under the conditions used for polymerization $[2,3]$.

Efforts to prepare perfluoro-1,5-hexadiene, perfluoro1,6-heptadiene, and perfluoro-1,7-octadiene were based on a synthesis that involved the telomerization of various fluoroiodoethanes, especially 1,2-dichlorotrifluoro 1-iodoethane with tetrafluoro-ethylene, e.g.,

$$
\mathrm{CF}_{2} \mathrm{ClCFClI}+\mathrm{CF}_{2} \mathrm{CF}_{2} \underset{\gamma}{\longrightarrow} \mathrm{CF}_{2} \mathrm{ClCFCl}\left(\mathrm{CF}_{2} \mathrm{CF}_{2}\right)_{n} \mathrm{I}
$$

where $n=1,2,3,4$, etc. The work described here does not involve telomers higher than $n=3$. The ethane derivative metioned was obtained by the addition of iodine monochloride to chlorotrifluoroethylene in such fashion that the ionic mode of addition was almost total. In a glass reaction-chamber, at temperatures $\leqslant 0{ }^{\circ} \mathrm{C}$, the yield of the desired isomer is 98 percent. As the temperature rises, according to Hauptschein [7], the free-radical mechanism begins to compete with ionic addition, producing increasing proportions of the isomeric 1,1-dichloroethane as illustrated.

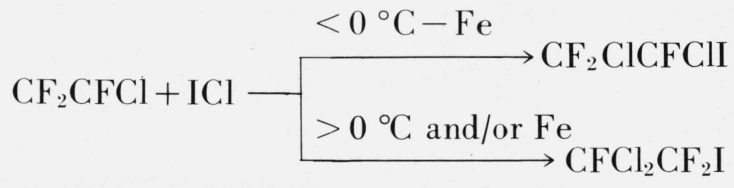

Hauptschein [7] and Knunyants [8] have made extensive studies of this reaction, and have modified and extended the work of Haszeldine [9]. Knunyants asserted that isomer $\mathrm{A}$ is four times as active as isomer $\mathrm{B}$ in initiating telomerization and various other reactions. Telomers prepared from isomer A may be dechlorinated in the final step, to produce the second double bond in the diene, whereas, obviously, telomers produced from isomer $\mathrm{B}$, having both chlorine atoms on the same carbon atom, will not. The efficiency of a telomerization in preparing perfluorodiene precursors is accordingly limited by the purity of the $\mathrm{A}$ isomer used as the starting material.

The telomerization illustrated may be adjusted to give maximal yields of the iodobutane, the iodohexane, or the iodooctane by varying the mole ratio of tetrafluoroethylene to the iodoethane, provided that there is a minimum of empty space in the reaction vessel. With a large vapor space in the reaction vessel, usually a steel bomb, and by use of gamma-ray initiation, much of the tetrafluoroethylene tends to polymerize in the vapor space, to form high polymer which drops into the liquid phase (consisting of the iodoethane and dissolved tetrafluoroethylene). High mole-ratios of tetrafluoroethylene to iodoethane produce high yields of hexane and octane, but, unfortunately, also increase the yields of telomers where $n \geqslant 4$ which are useless in the preparation of dienes that will undergo the cyclic mechanism of polymerization. All of the telomers used as precursors were clear, colorless liquids that turned violet and, finally, deep purple on standing. Their physical constants are shown in table 1 .

TABLE 1. Telomers of $\mathrm{CF}_{2} \mathrm{ClCFClI}$ and $\mathrm{CF}_{2} \mathrm{CF}_{2}$

\begin{tabular}{l|c|c|l}
\hline \hline \multicolumn{1}{c|}{ Compound } & B.P. ${ }^{\circ} \mathrm{C} / \mathrm{mm}$ & M.P. ${ }^{\circ} \mathrm{C}$ & \multicolumn{1}{|c}{$\mathrm{N}_{\mathrm{D}}^{20}$} \\
\hline \hline $\mathrm{CF}_{2} \mathrm{ClCFClI}$ & $101^{\circ}, 53 / 150$ & & \\
$\mathrm{CF}_{2} \mathrm{ClCFClCF} \mathrm{CF}_{2} \mathrm{I}$ & $140^{\circ}, 66 / 67$ & & 1.4046 \\
$\mathrm{CF}_{2} \mathrm{ClCFCl}\left(\mathrm{CF}_{2} \mathrm{CF}_{2}\right)_{2} \mathrm{I}$ & $83 / 35$ & & 1.3830 \\
$\mathrm{CF}_{2} \mathrm{ClCFCl}\left(\mathrm{CF}_{2} \mathrm{CF}_{2}\right)_{3} \mathrm{I}$ & $82 / 3$ & 24 & $1.3710\left(\right.$ at $\left.25^{\circ}\right)$ \\
$\mathrm{CF}_{2} \mathrm{ClCFCl}\left(\mathrm{CF}_{2} \mathrm{CF}_{2}\right)_{4} \mathrm{I}$ & $110 / 7$ & 70 & \\
\hline \hline
\end{tabular}

By cross coupling 1,2-dichloro-heptafluoro-4iodobutane and 1,2-dichloro-trifluoro-1-iodoethane, three products were obtained [10], namely, 1,2,3,4tetrachlorohexafluorobutane, 1,2,5,6-tetrachloroperfluorohexane, and 1,2,7,8-tetrachloroperfluorooctane. 
Dechlorination of these intermediates produced, respectively, perfluoro-1,3-butadiene, perfluoro-1,5hexadiene, and perfluoro-1,7-octadiene. It is apparent that perfluoro-1,3-butadiene and perfluoro-1,7-octadiene may be prepared by homocoupling the iodo- ethane and/or the iodobutane mentioned, and by dechlorinating the respective tetrachloro compounds. Other syntheses of perfluoro-1,5-hexadiene are outlined later. Starting materials were, in all experiments, the telomers already discussed, listed in table 1.

1.

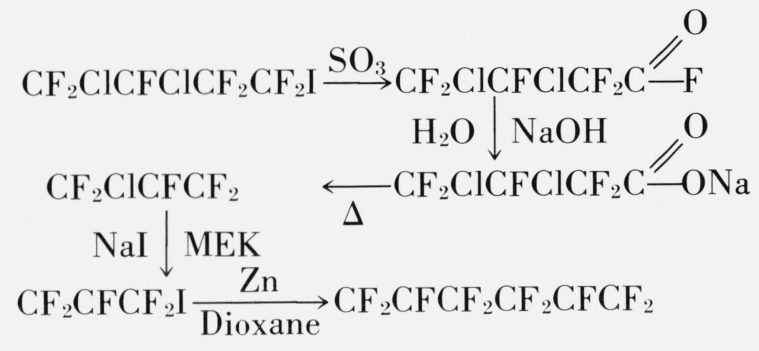

2.

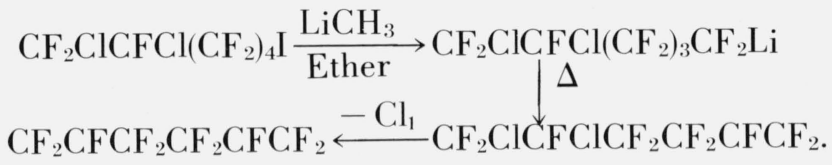

In reaction 1 , the reaction with sulfur trioxide was reported by Knunyants [11] and the coupling of perfluoroallyiodide was described by Miller [12]. Efforts to prepare perfluoro-1,5-hexadiene by the following reaction were unsuccessful.

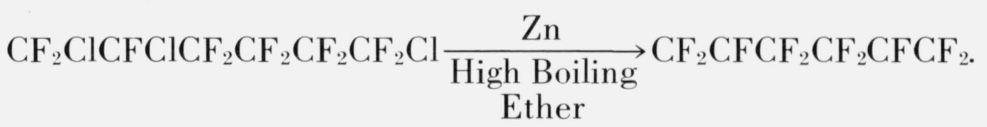

Instead of dechlorofluorination, inter-intramolecular dechlorination occurred, yielding perfluoro-1, 11dodecadiene.

Efforts to synthesize perfluoro-1,6-hepatadiene, a previously unreported compound, resulted in a large number of interesting intermediates, some of which are also unreported compounds. The various syntheses are outlined.

1.

$$
\begin{array}{r}
\mathrm{H}\left(\mathrm{CF}_{2}\right)_{6} \mathrm{CH}_{2} \mathrm{OH} \frac{\mathrm{Na}_{2} \mathrm{Cr}_{2} \mathrm{O}_{7}}{\mathrm{H}_{2} \mathrm{O}+\mathrm{H}_{2} \mathrm{SO}_{4}} \mathrm{H}\left(\mathrm{CF}_{2}\right)_{6} \mathrm{C}(\mathrm{F})(\mathrm{OH})_{2} \stackrel{\mathrm{SF}_{4}}{\longrightarrow} \mathrm{H}\left(\mathrm{CF}_{2}\right)_{7} \mathrm{H} \\
\mathrm{CF}_{2} \mathrm{CF}\left(\mathrm{CF}_{2}\right)_{3} \mathrm{CFCF}_{2} .
\end{array}
$$

This effort was unsuccessful. The oxidation step produced the aldehyde hydrate in good yield, but yields in the sulfur tetrafluoride reaction ranged from low

to zero. Efforts to effect dehydrofluorination were completely unsuccessful. The intermediates were isolated, purified and characterized.
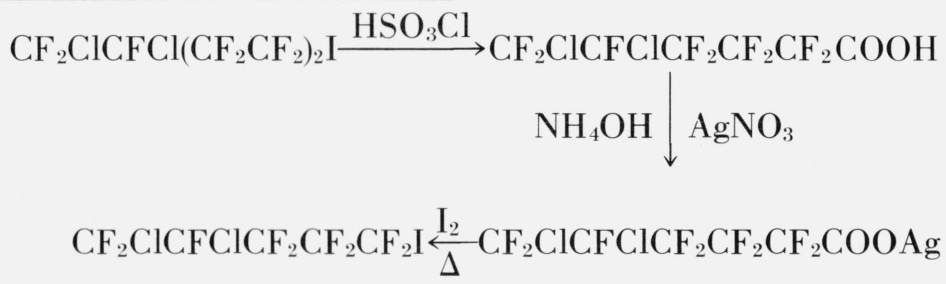

$$
\mathrm{Zn} \mid \begin{aligned}
& \text { High } \\
& \text { Boiling } \\
& \text { Ether }
\end{aligned}
$$

$\mathrm{CF}_{2} \mathrm{CF}\left(\mathrm{CF}_{2}\right)_{3} \mathrm{CFCF}_{2}$ 
The chlorosulfonic acid reaction utilized in syntheses 2 and 5 was reported by Hauptschein [13]. The highboiling ether mentioned in synthesis 2 and used in all subsequent dechlorinations was bis[2-(2-methoxyethoxy)ethyl] ether. Fluorodienes prepared and their respective boiling points are listed in table 2 .

TABLE 2. Fluorodienes

\begin{tabular}{c|r}
\hline \hline $\mathrm{CF}_{2} \mathrm{CF}\left(\mathrm{CF}_{2}\right)_{n} \mathrm{CFCF}_{2}$ & B.P. ${ }^{\circ} \mathrm{C}$ \\
\hline$n=0$ & 7 \\
$n=1$ & 36 \\
$n=2$ & 59 \\
$n=3$ & 84 \\
$n=4$ & 106 \\
\hline
\end{tabular}

\section{Experimental Procedure}

\subsection{Preparation of 4-Chloroperfluoro-1,6-heptadiene}

4,6,7-Trichloroperfluoroheptene-1: This compound was prepared in the manner of Park and Lacher [4]. Eleven kilograms $(5 \mathrm{~mol})$ of 3,5,7,8-tetrachloroper- fluorooctanoic acid was added to $200 \mathrm{~g}(5 \mathrm{~mol})$ of sodium hydroxide dissolved in 3 liters of water. The mixture was carefully adjusted to $\mathrm{pH} 7$ and chilled. The sodium salt was filtered with suction apparatus, dried in air, and placed in a strong vacuum for several days. The resulting salt was anhydrous and extremely hygroscopic.

Eleven $\mathrm{kg}$ of dry sodium salt was pyrolyzed under reduced pressure in a stainless steel tube connected through adapters to a series of dry ice acetone-cooled traps. The pyrolysis temperature was approximately $350{ }^{\circ} \mathrm{C}$, produced by a furnace controlled by two 10-A variable voltage transformers. Pyrolysis proceeded rapidly and smoothly, producing $1,560 \mathrm{~g}$ of crude product or 83 percent. This was washed with three portions of 10 percent aqueous potassium hydroxide, each portion about 10 percent of the volume of fluorocarbon, then with similar portions of water. The washed material was dried over anhydrous sodium sulfate and distilled under reduced pressure. The yield was $1,400 \mathrm{~g}$ of pure 4,6,7-trichloroperfluoroheptene-1, or 75 percent. A higher boiling material which gave a single peak on the vapor-phase chromatograph amounted to $60 \mathrm{~g}$ B.P. $40^{\circ} \mathrm{C} / 1 \mathrm{~mm}$.

4-Chloroperfluoroheptadiene-1,6: In a 2-liter flask equipped with stirrer, reflux condenser, and dropping 
funnel a mixture of $50 \mathrm{ml}$ of bis [2(2-methoxyethoxy) ethyl] ether and $140 \mathrm{~g}$ of zinc dust, which had been treated with $100 \mathrm{ml}$ of hydrochloric acid while suspended in acetone, filtered, and dried under vacuum for $4 \mathrm{~h}$, was gently heated to about $60^{\circ} \mathrm{C}$ with stirring. To this mixture was added $200 \mathrm{~g}(0.5 \mathrm{~mol})$ of 4,6,7trichloroperfluoroheptene-1 with continued stirring. Heating was increased until refluxing was observed, then discontinued until addition was complete. The mixture was then gently refluxed for $\mathrm{l} h$ and permitted to cool to room temperature. The heptene and heptadiene were removed from the mixture by attaching a series of dry ice acetone-cooled traps to the condenser and applying a vacuum of less than $1 \mathrm{~mm}$ of mercury to the system. The solvent did not distill. The mixture of heptene and heptadiene was distilled at $75 \mathrm{~mm}$. Three fractions were collected, between 35 and 45 , between 45 and 50 , and between 50 and $70^{\circ} \mathrm{C}$. A vapor-phase study showed the first fraction to be two-thirds heptadiene and two lower boiling components. The 45-50 fraction was almost pure heptadiene, while the 50-70 fraction contained small amounts of heptadiene and two higher boiling components. Above $70{ }^{\circ} \mathrm{C}$ virtually pure starting material was recovered. About 10 percent of the starting material remained in the solvent, and upon distillation of the solvent was converted into tar. Approximately $60 \mathrm{~g}$ of dechlorination products was estimated to be the desired heptadiene, or about 35 percent conversion on each dechlorination. The starting material was recycled.

The purest fraction obtained from distillation was run through a vapor-phase chromatograph and was found to contain trace amounts of all other dechlorination products. These trace materials were carefully removed through preparatory-scale vapor-phase chromatography before any attempt to polymerize or telomerize the compound was made. The pure heptadiene boiled at $112{ }^{\circ} \mathrm{C} / 760 \mathrm{~mm}$, which compares well with Park's $103^{\circ} / 633 \mathrm{~mm}$.

\subsection{Preparation of Perfluoropentadiene}

Preparation of Sodium 3,5,6-Trichlorooctafluorohexanoate. In a 4 -liter beaker, $320 \mathrm{~g}(8 \mathrm{~mol})$ of sodium hydroxide was dissolved in 2 liters of water. The solution was vigorously stirred and $2915 \mathrm{~g}(8 \mathrm{~mol})$ of $3,5,6-$ trichlorooctafluorohexanoic acid was added. The solution became very viscous, but there was no precipitate. Chilling produced no precipitate, so the solution was poured into a clean vacuum desiccator and evaporated to near dryness by using an infrared lamp and an aspirator. The salt became syrupy, buttery, and then waxy, but did not crystallize. The salt was then dried at $10^{-2-2}$ $\mathrm{mm}$ (dry ice acetone trap) for three days. Water $(500$ $\mathrm{ml}$ ) was removed, and the wax became a white, crystalline material. Drying was continued for two more days, with removal of water $(200 \mathrm{ml})$, and the crystals became a fine, apparently amorphous, rather hygroscopic powder.
Pyrolysis of Sodium 3,5,6-Trichlorooctafluorohexanoate. 3,5,6-Trichlorooctafluorohexanoate $(2.2 \mathrm{~kg})$ was pyrolyzed under reduced pressure in a stainless steel tube connected, through adapters, to a series of cooled traps (dry ice acetone) and heated to approximately $350{ }^{\circ} \mathrm{C}$ in a furnace controlled by two $10 \mathrm{~A}$, variable transformers. Pyrolysis took place smoothly, yielding $1520 \mathrm{~g}$ of products (theoretical yield, $1600 \mathrm{~g}$ ). This was 95 percent based on the salt. The product was carefully distilled through a 10-in glass column packed with glass helices. A fraction boiling at $91{ }^{\circ} \mathrm{C}$ was collected as the desired product. It amounted to $1360 \mathrm{~g}(85 \%$, based on the acid salt).

ANAL. Calcd. for $\mathrm{C}_{5} \mathrm{Cl}_{2} \mathrm{~F}_{8}$ : C, $21.2 \%$; Cl, 25.1\%; F, $53.7 \%$. Found: C, $21.0 \%$; Cl, $24.8 \%$.

In the same distillation, a second fraction was obtained, boiling at $120{ }^{\circ} \mathrm{C}$. This amounted to $145 \mathrm{~g}(9 \%$ based on the acid salt). The remaining material would not distill at atmospheric pressure, and was assumed to be a coupling product. No further effort was made to characterize it. The $120{ }^{\circ} \mathrm{C}$ fraction showed three peaks on a gas-liquid chromatogram, and a deep, split band between 5 and $6 \mu$ in its infrared spectrum. This appeared to be a mixture of the isomers of trichloroheptafluoropentene. This was supported by the elemental analysis and by conversion into a mixture of a three monochloroheptafluoropentadienes.

ANAL. Calcd. for $\mathrm{C}_{5} \mathrm{Cl}_{3} \mathrm{~F}_{7}$ : C, $20.3 \%$; Cl, $35.2 \%$. Found: C, 20.1\%; Cl, 34.9\%.

Dechlorination of 4,5-Dichlorooctafluoro-1-pentene. Dechlorination was effected by a slight variation of the method of Park and Lacher [4]. In a beaker, $130 \mathrm{~g}$ $(2.0 \mathrm{~mol})$ of powdered zinc was suspended in acetone, and $100 \mathrm{ml}$ of concentrated hydrochloric acid was added slowly with stirring. Stirring was continued for $30 \mathrm{~min}$. The zinc was filtered off with suction, washed thoroughly with acetone, dried briefly in air, and then overnight in a vacuum oven at $70{ }^{\circ} \mathrm{C}$. This activated zinc was placed in a $500-\mathrm{ml}$, three-necked flask (equipped with an efficient stirrer, a dropping funnel, and a 6-in glass column packed with glass helices and topped by a still-head) and $200 \mathrm{ml}$ of bis[2-(2-methoxyethoxy)ethyl] ether was added. Stirring was commenced, and the flask was heated (Thermowell heater) to $70{ }^{\circ} \mathrm{C}$. 4,5-Dichlorooctafluoro-1-pentene $(284 \mathrm{~g}, 1$ mol) was added in small portions until the reaction started, and then dropwise until addition was complete, Perfluoropentadiene distilled out of the column at about the same rate as the pentene was added. The rate of addition of the pentene and the heat applied to the flask were so controlled that the temperature of the distillate never exceeded $40{ }^{\circ} \mathrm{C}$. The yield of crude pentadiene was $194 \mathrm{~g}(91 \%)$; this was distilled through a 10-in glass column, packed with glass helices, yielding a pure product, boiling at $36^{\circ} \mathrm{C}$, that showed one major peak (and two minor peaks with $1 \%$ and $0.3 \%$ of the area of the major peak) on an analytical gas-liquid chromatogram. The yield of pure compound was $160 \mathrm{~g}$ $(89 \%)$. Recovered starting material $(34 \mathrm{~g})$ was recycled. Its infrared spectrum showed a single band at $5.6 \mu$, the band being somewhat broader and more intense 
than that of the parent compound. Elemental analysis confirmed the composition of the diene.

ANAL. Calcd. for $\mathrm{C}_{5} \mathrm{~F}_{8}$ : C, 28.3\%; F, 71.7\%. Found: C, $28.1 \%$; F, $70.9 \%$.

Dechlorination of Trichloroheptafluoropentene Fraction. The dechlorination procedure described for the preparation of perfluoro-1,4-pentadiene was repeated. A $60 \mathrm{~g}(0.2 \mathrm{~mol})$ portion of the trichloroheptafluoropentene fraction was added to the flask containing the high-boiling ether and activated zinc. During the dechlorination, the distillate came over below $70{ }^{\circ} \mathrm{C}$. The crude yield was $42 \mathrm{~g}$ or $92 \%$. Upon careful distillation at $65^{\circ} \mathrm{C}, 39 \mathrm{~g}$ of a mixture of monochloroheptafluoropentadienes was obtained, which was 85 percent based on the pentene; $5 \mathrm{~g}$ of starting material was recovered and recycled.

ANAL. Calcd. for $\mathrm{C}_{5} \mathrm{ClF}_{7}$ : C, $26.3 \%$ : Cl, $15.5 \%$; F, $58.2 \%$. Found: C, $26.6 \%$; Cl, $15.2 \%$; F, $58.1 \%$.

\subsection{Telomer Studies}

Addition of Iodine Monochloride to Trifluoroethylene. In an 800-ml stainless steel bomb $238 \mathrm{~g}$ $(2.9 \mathrm{~m})$ of trifluoroethylene and $454 \mathrm{~g}(2.8 \mathrm{~m})$ of iodine monochloride were shaken for $24 \mathrm{~h}$ at room temperature. The small excess of the ethylene was permitted to escape. The yield was $650 \mathrm{~g}$ of material boiling at $84{ }^{\circ} \mathrm{C}$ or 95 percent based on iodine monochloride.

Addition of Iodine Monochloride to Tetrafluoroethylene. In an 800-ml stainless steel bomb $100 \mathrm{~g}(1 \mathrm{~m})$ of tetrafluoroethylene and $162 \mathrm{~g}(1 \mathrm{~m})$ of iodine monochloride was shaken at room temperature for $24 \mathrm{~h}$. The contents were removed from the bomb, shaken with aqueous sodium bisulfite, dried over anhydrous sodium sulfate and distilled. The yield was $200 \mathrm{~g}$ of clear liquid boiling at $56^{\circ} \mathrm{C}$ or 76.5 percent based on either reagent.

Addition of Iodine to Tetrafluoroethylene. In a 1400 $\mathrm{ml}$ bomb was placed $254 \mathrm{~g}(1.0 \mathrm{~m})$ of $\mathrm{I}_{2}$ and $210 \mathrm{~g}(1.0 \mathrm{~m})$ of $\mathrm{CF}_{2} \mathrm{Br}_{2}$. Through a vacuum line $100 \mathrm{~g}(1.0 \mathrm{~m})$ of tetrafluoroethylene was distilled into the bomb. The bomb and its contents were rocked for 2 days at room temperature without diminution of pressure. The temperature was raised to $100^{\circ}$ for $16 \mathrm{~h}$ and shaking was continued. The bomb was cooled to room temperature and the internal pressure was found to have decreased from 150 psi to atmospheric. A solution weighing $450 \mathrm{~g}$ was transferred from the bomb to a distilling flask. From this solution $140 \mathrm{~g}$ of dibromodifluoromethane and $40 \mathrm{~g}$ of iodine were recovered. The product, 1,2-diodotetrafluoroethane amounted to $210 \mathrm{~g}$ of a purple liquid boiling at 112 to $113{ }^{\circ} \mathrm{C}$ or 62.1 percent based on the tetrafluoroethylene.

Addition of Iodine Monochloride to Chlorotrifluoroethylene. A 12-liter three-neck flask equipped with a stirrer and dropping funnel was placed in a constant temperature bath set at $-10{ }^{\circ} \mathrm{C}$ and fastened securely. Into it was poured $5000 \mathrm{ml}$ of clean dry methylene chloride. Dropwise 2500 g 15.4 mol of iodine monochloride was added. The dropping funnel was replaced with a dry ice acetone-cooled condenser.
Through the third neck $1830 \mathrm{~g}(16.0 \mathrm{~m})$ of chlorotrifluoroethylene was distilled directly from the cylinder. Stirring and gentle refluxing of the ethylene was continued for six weeks. The flask was then removed from the bath and permitted to warm to room temperature. The unreacted ethylene was distilled into a dry ice acetone-cooled trap and saved for the next run. The contents of the flask were removed, the methylene chloride distilled and the product was fractionated through a 10-in column packed with helices. The forecut consisted of two fractions boiling at $46^{\circ} \mathrm{C}$ and $54{ }^{\circ} \mathrm{C}$. The desired product, $\mathrm{CF}_{2} \mathrm{ClCFClI}$, boiling at $101{ }^{\circ} \mathrm{C}$ amounted to $3100 \mathrm{~g}$ or 72.6 percent based on the iodine monochloride which was not chemically pure. A considerable quantity of iodine remained in the reaction flask.

Addition of Iodine Monochloride to Chlorotrifluoroethylene. In a 1400-ml steel bomb was placed $1000 \mathrm{~g}(6.2 \mathrm{~m})$ of technical grade iodine monochloride. The bomb was cooled to $-196^{\circ}$ using liquid nitrogen and into it was distilled $727 \mathrm{~g}(6.25 \mathrm{~m})$ of chlorotrifluoroethylene. The bomb was permitted to warm to room temperature while rocking. It was then rocked for $65 \mathrm{~h}$ at room temperature. At the end of this period the contents were removed, shaken with aqueous sodium bisulphite and dried over anhydrous sodium sulfate. The amount of crude product was $1510 \mathrm{~g}$ or 88 percent based on the impure iodine monochloride. Distillation produced a forecut boiling below $50{ }^{\circ} \mathrm{C}$ and $1415 \mathrm{~g}$ of product boiling at $101{ }^{\circ} \mathrm{C}$ or 82.5 percent based on iodine monochloride. This product was found to be a mixture of isomers $\mathrm{CF}_{2} \mathrm{ClCFClI}$ and $\mathrm{CF}_{2} \mathrm{ICFCl}_{2}$, but was largely the latter.

Telomerization of 1-Chloro-1,1.2-trifluoro-2-iodoethane with Tetrafluoroethylene. A glass tube containing $47.6 \mathrm{~g}(0.2 \mathrm{~m})$ of $\mathrm{CF}_{2} \mathrm{ClCFHI}$ and $20 \mathrm{~g}(0.2 \mathrm{~m})$ of $\mathrm{CF}_{2} \mathrm{CF}_{2}$ was subjected to ordinary room light for a brief period at $0{ }^{\circ} \mathrm{C}$. Upon warming to $0^{\circ}$ from $-196{ }^{\circ} \mathrm{C}$ solid polymer began forming immediately. After all action had apparently ceased the tube was opened and any remaining $\mathrm{CF}_{2} \mathrm{CF}_{2}$ was permitted to escape. Resolution of the mixture yielded $33 \mathrm{~g}$ of the starting ethane, $3 \mathrm{~g}$ of very high boiling viscous liquid product and $5 \mathrm{~g}$ of solid polymer, both assumed to be low molecular weight polytetrafluoroethylene.

Telomerization of 1-Chloro-tetrafluoro 2-iodoethane with Tetrafluoroethylene. A glass tube charged with $49.6 \mathrm{~g}(0.19 \mathrm{~m})$ of $\mathrm{CF}_{2} \mathrm{ICF}_{2} \mathrm{Cl}$ and $18.8 \mathrm{~g}(0.19 \mathrm{~m})$ of $\mathrm{CF}_{2} \mathrm{CF}_{2}$ was permitted to warm from $-195{ }^{\circ} \mathrm{C}$ to room temperature. It was subjected to ordinary fluorescent light for $8 \mathrm{~h}$ at room temperature then opened. Separation of the components of this mixture yielded $35 \mathrm{~g}$ of original ethane $3 \mathrm{~g}$ of material boiling between $60^{\circ}$ and $120^{\circ} \mathrm{C}$ and $11 \mathrm{~g}$ of polymer. Excess ethylene again was permitted to escape.

Telomerization of tetrafluoro 1,2-Diiodoethane with Tetrafluoroethylene. A glass tube containing $65.4 \mathrm{~g}$ $(0.184 \mathrm{~m})$ of $\mathrm{CF}_{2} \mathrm{ICF}_{2} \mathrm{I}$ and $18.4 \mathrm{~g}(0.184 \mathrm{~m})$ of $\mathrm{CF}_{2} \mathrm{CF}_{2}$ was subjected for three days to radiation from a cobalt 60 source at a dose rate of 0.25 megarads/h. The yields were as follows: 


\begin{tabular}{l|l|c}
\hline \hline \multicolumn{1}{c|}{ B.P. } & $\begin{array}{c}\text { Postulated } \\
\text { product }\end{array}$ & Yield \\
\hline $46^{\circ} \mathrm{C} / 65 \mathrm{~mm}$ & $\mathrm{CF}_{2} \mathrm{ICF}_{2} \mathrm{I}$ & $16.0 \mathrm{~g}$ \\
$55^{\circ} \mathrm{C} / 25$ & $\left.\mathrm{I}^{\circ} \mathrm{CF}_{2}\right)_{4} \mathrm{I}$ & 11.5 \\
$52^{\circ} \mathrm{C} / 1$ & $\mathrm{I}\left(\mathrm{CF}_{2}\right)_{6} \mathrm{I}$ & 4.0 \\
\hline
\end{tabular}

Telomerization of 1,2-Dichlorotrifluoro-1-iodoethane with Tetrafluoroethylene. Into a thick-walled glass tube containing $500 \mathrm{~g}(1.8 \mathrm{~m}) \mathrm{CF}_{2}$ ClCFCII was distilled $192 \mathrm{~g}$ $(1.9 \mathrm{~m})$ of $\mathrm{CF}_{2} \mathrm{CF}_{2}$. The tube was thoroughly degassed and placed in a cobalt-60 source where it was subjected to a dose rate of 0.25 megorads $/ \mathrm{h}$ for $20 \mathrm{~h}$. It was then cooled to $-196^{\circ} \mathrm{C}$ with liquid nitrogen and opened. On warming to room temperature excess tetrafluoroethylene was permitted to escape. The liquid mixture was transferred to a distilling flask and distilled, first roughly then carefully through a 10 -in column packed with glass helices. The yields of telomers were as follows:

\begin{tabular}{c|l|r}
\hline \hline & & \\
$99-101^{\circ}$ & $\mathrm{CF}_{2} \mathrm{ClCFClI}$ & $91 \mathrm{~g}$ \\
$101-140^{\circ}$ & & 19 \\
141 & $\mathrm{CF}_{2} \mathrm{ClCFCl}\left(\mathrm{CF}_{2}\right)_{2} \mathrm{I}$ & 196 \\
$25-44 / 1 \mathrm{~mm}$ & & 20 \\
$46 / 1 \mathrm{~mm}$ & $\mathrm{CF}_{2} \mathrm{ClCFCl}_{\left(\mathrm{CF}_{2}\right)_{4} \mathrm{I}}$ & 95 \\
$64 / 1 \mathrm{~mm}$ & $\mathrm{CF}_{2} \mathrm{ClCFCl}_{\left(\mathrm{CF}_{2}\right)_{6} \mathrm{I}}$ & 30 \\
$>64 / 1 \mathrm{~mm}$ & higher telomers & 20 \\
\hline
\end{tabular}

Telomerization of 3,4-Dichloroheptafluoro-1-iodobutane with Tetrafluoroethylene. A large thick-walled glass tube containing $495 \mathrm{~g}(1.31 \mathrm{~m})$ of $\mathrm{CF}_{2} \mathrm{ClCFCl}\left(\mathrm{CF}_{2}\right)_{2} \mathrm{I}$ and $117 \mathrm{~g}(1.17 \mathrm{~m})$ of tetrafluoroethylene was subjected to $\gamma$ radiation at a dose rate of 2.5 megarads $/ \mathrm{h}$ for $12 \mathrm{~h}$. The tube was opened and its contents filtered. The liquid fraction was carefully distilled. The total yields are listed as follows:

$$
\begin{array}{cc}
\text { Recovered } \mathrm{CF}_{2} \operatorname{ClCFCl}\left(\mathrm{CF}_{2}\right)_{2} \mathrm{I} & 164 \mathrm{~g} \\
\mathrm{CF}_{2} \operatorname{ClCFCl}\left(\mathrm{CF}_{2}\right)_{4} \mathrm{I} & 127 \\
\mathrm{CF}_{2} \operatorname{ClCFCl}\left(\mathrm{CF}_{2}\right)_{6} \mathrm{I} & 52 \\
\mathrm{CF}_{2} \operatorname{ClCFCl}\left(\mathrm{CF}_{2}\right)_{n} \mathrm{I}, n \geqslant 8 & 85 \\
\text { High polymer } & 76
\end{array}
$$

Telomerization of 1,2-Dichloro-trifluoro-1-iodoethane with Hexafluoropropylene. Into a $1400-\mathrm{ml}$ bomb was poured $560 \mathrm{~g}(2 \mathrm{~m})$ of 1,2-dichloro-1-iodotrifluoroethane. The bomb was attached to a vacuum line cooled to $-196{ }^{\circ} \mathrm{C}$ and evacuated. Into it was distilled $800 \mathrm{~g}$ $(5.3 \mathrm{~m})$ of carefully degassed hexafluoropropylene. The bomb was sealed and placed in a heater-rocker assembly, heated to $200^{\circ}$, and rocked at this temperature for $294 \mathrm{~h}$. It was then cooled to room temperature and $210 \mathrm{~g}$ of excess hexafluoropropylene was distilled into a dry ice-acetone cooled trap. The liquid product, $710 \mathrm{~g}$ of a dark oil was distilled and the following absolute yields were obtained. It is to be noted that percentage yields are not particularly informing in this type of telomerization.

\begin{tabular}{c|r|c|c}
\hline \hline$<100{ }^{\circ} \mathrm{C}$ & $30 \mathrm{~g}$ & $97-104 / 20 \mathrm{~mm}$ & $88 \mathrm{~g}$ \\
& & $145-55 / 20 \mathrm{~mm}$ & \\
$100-140$ & 39 & $75-85 / 1 \mathrm{~mm}$ & 154 \\
$56-61 / 20 \mathrm{~mm}$ & 110 & $186-186 / 20 \mathrm{~mm}$ & 122 \\
$61-96 / 20 \mathrm{~mm}$ & 7 & $>200 / 20 \mathrm{~mm}$ & 157 \\
\hline
\end{tabular}

Telomerization of 1,2-Dichloro-heptafluoro-4-iodobutane with Hexafluoropropylene. Into a 1400-ml bomb was placed $760 \mathrm{~g}(2 \mathrm{~mm})$ of 1,2-dichloro-4-iodoheptafluorobutane. The bomb was attached to a vacuum line cooled to $-195{ }^{\circ} \mathrm{C}$ and evacuated. Into it was distilled $470 \mathrm{~g}(3.14 \mathrm{~m})$ of carefully degassed hexafluoropropylene. The bomb was sealed, placed in a heaterrocker mechanism, heated to $202{ }^{\circ} \mathrm{C}$ and rocked at this temperature for $411 \mathrm{~h}$. It was then cooled to room temperature and attached to a dry ice acetone-cooled trap. In this way about $50 \mathrm{~g}$ of impure hexafluoropropylene was recovered. Total amount of liquid (or solid) product was $1071 \mathrm{~g}$. The liquid was distilled roughly under reduced pressure giving the following yields.

$$
\begin{array}{ll}
<130^{\circ} / 20 \mathrm{~mm} & 546 \mathrm{~g} \\
>130^{\circ} / 20 \mathrm{~mm} & 247 \\
\text { Residue } & 170
\end{array}
$$

A careful distillation of the first fraction yielded the following:

$$
\begin{array}{rcr}
<92^{\circ} / 20 \mathrm{~mm} & 19 \mathrm{~g} \\
92-94^{\circ} / 20 \mathrm{~mm} & 372 \quad\left[\mathrm{CF}_{2} \mathrm{ClCFCl}\left(\mathrm{CF}_{2}\right)_{3} \mathrm{CFCF}_{1}\right] \\
95-130^{\circ} / 20 \mathrm{~mm} & 148
\end{array}
$$

Preparation of 1,5,6-Trichloroperfluorohexane. In each of two quartz tubes was placed $67 \mathrm{~g}(0.14 \mathrm{~m})$ of $\mathrm{CF}_{2} \mathrm{ClCFCl}\left(\mathrm{CF}_{2}\right)_{4} \mathrm{I}$ and $28.4 \mathrm{~g}(0.4 \mathrm{~m})$ of chlorine. The tubes were shaken and irradiated with ultraviolet light from a Hanovia type $\mathrm{L}$ burner for $13 \mathrm{~h}$. The tubes were opened and the excess chlorine permitted to escape. The liquid mixtures were combined and distilled. The amount of desired product was $65 \mathrm{~g}$ or 61.8 percent conversion. Thirty nine grams of iodocompound were recovered unchanged. Taking this into consideration the yield was 84.1 percent. A small residue was not identified. Boiling point of the slightly impure material was $146^{\circ} \mathrm{C}$.

Dehalogenation of 1,5,6-Trichloroperfluorohexane. In a 1-liter flask equipped with a still head and stirrer $61 \mathrm{~g}(0.17 \mathrm{~m})$ of $\mathrm{CF}_{2} \mathrm{ClCFCl}\left(\mathrm{CF}_{2}\right)_{4} \mathrm{Cl}, 60 \mathrm{~g}\left(0.9 \mathrm{~m}\right.$ of $\mathrm{Z}_{\mathrm{n}}$ $90 \mathrm{ml}$ of acetic anhydride and $270 \mathrm{ml}$ of acetic acid was stirred and heated to $90^{\circ}$. The 6-chloroperfluoro-1hexane distilled. The crude product was washed with water, dried over anhydrous sodium sulfate and redistilled. Yield of pure product was $27 \mathrm{~g}$ or 54 percent B.P. $89^{\circ}$. 
Attempted Dechlorofluorination of 6-Chloroperfluoro-1-hexene. In a 1-liter flask equipped with a stirrer, reflux condenser, and a thermometer extending into the liquid were placed $30 \mathrm{~g}(0.09 \mathrm{~m})$ of $\mathrm{CF}_{2}=\mathrm{CF}\left(\mathrm{CF}_{2}\right)_{4} \mathrm{Cl}, 13 \mathrm{~g}(0.2 \mathrm{~m})$ of $\mathrm{Zn}$ and $200 \mathrm{ml}$ of diethylene glycol. The mixture was stirred and heated to $140{ }^{\circ} \mathrm{C}$, the hexane refluxing vigorously. At $140^{\circ}$ the contents of the flask began to seethe and froth and the refluxing subsided. No further reflux was observed until the temperature reached $190^{\circ}$. The reflux condenser was replaced with a still head and a product was distilled at $182^{\circ} \mathrm{C}$. This is the B.P. that Knunyants has reported for perfluoro-1,11-dodecadiene. The yield was $13 \mathrm{~g}$ or 50 percent.

Coupling of 1,2-Dichloro-heptafluoro 4-iodobutane (Haszeldine's Method). Three quartz tubes were prepared as described below.

\begin{tabular}{l|l|l|l}
\hline \hline & $\mathrm{CF}_{2} \mathrm{ClCFClCF}_{2} \mathrm{CFF}_{2} \mathrm{I}$ & \multicolumn{1}{|c|}{$\mathrm{H}_{4}$} & \multicolumn{1}{|c}{ Freom 112 } \\
\hline No. 1 & $40 \mathrm{~g}(0.106 \mathrm{~m})$ & $215 \mathrm{~g}$ & $32 \mathrm{~g}$ \\
No. 2 & $37 \mathrm{~g}(0.097 \mathrm{~m})$ & 190 & 35 \\
No. 3 & $38 \mathrm{~g}(0.100 \mathrm{~m})$ & 170 & 33 \\
\hline
\end{tabular}

These tubes were shaked and irradiated with ultraviolet rays from a Hanovia Type $\mathrm{L}$ burner for $35 \mathrm{~h}$. The contents of the tubes were combined and the organic material was carefully separated from the mercury and distilled. The yield was $34 \mathrm{~g}$ of material, boiling at $68{ }^{\circ} \mathrm{C} / 3 \mathrm{~mm}$ or 68.5 percent based on the fluorocarbon, since $40 \mathrm{~g}$ of fluorobutane was recovered.

\section{(Knunyant's Method)}

In a 250-ml 3-neck flask, complete with stirrer, reflux condenser and dropping funnel, was placed a mixture of $10 \mathrm{~g}(0.15 \mathrm{~m})$ of powdered zinc in $31 \mathrm{~g}$ of acetic anhydride and $50 \mathrm{ml}$ of methylene chloride. This mixture was stirred vigorously and heated to reflux. To it was added dropwise $57 \mathrm{~g}(0.15 \mathrm{~m})$ of $\mathrm{CF}_{2} \mathrm{ClCFClCF}_{2} \mathrm{CF}_{2} \mathrm{I}$. During the addition, heating was discontinued but a vigorous reflux was maintained by the rate of addition. After addition, heating was resumed and reflux was maintained for $6 \mathrm{~h}$. The flask was cooled and its contents were filtered and added dropwise to 1 liter of water. The organic layer was separated, dried over anhydrous sodium sulfate and distilled. Careful distilllation thorugh a 10 -in column packed with glass helices yielded $22.4 \mathrm{~g}$ of a clear colorless liquid boiling at $68{ }^{\circ} \mathrm{C} / 3 \mathrm{~mm}$. This was 59.3 percent based on the dichloroiodoperfluorobutane.

Cross-coupling of 1,2-Dichlorotrifluoro-1-iodoethane and 1,2-Dichloro-perfluoro 4-iodobutane. Into a 3-liter, 3 -neck flask equipped with a stirrer reflux condenser and dropping funnel was placed a mixture of $260 \mathrm{~g}$ $(4.0 \mathrm{~m})$ of zinc powder, $800 \mathrm{ml}$ of acetic anhydride and $2000 \mathrm{ml}$ of methylene chloride. This mixture was stirred and heated to reflux. To this refluxing mixture was added dropwise an intimate mixture of $556 \mathrm{~g}(2 \mathrm{~m})$ 1,2-dichloro-trifluoro-1-iodoethane and $760 \mathrm{~g}(2 \mathrm{~m})$ of 1,2-dichloro-4-iodoperfluorobutane. During the addition of the halocarbon mixture reflux was maintained without application of external heat. When addition was complete reflux and stirring were continued overnight. The contents of the flask were filtered and the residue discarded. The filtrate was added slowly with stirring to $5000 \mathrm{ml}$ of water in two 4-liter beakers. The aqueous layer was discarded. The methylene chloride solution was dried over anhydrous sodium sulfate and distilled. It was then redistilled through an 18-in column packed with glass helices with the following results.

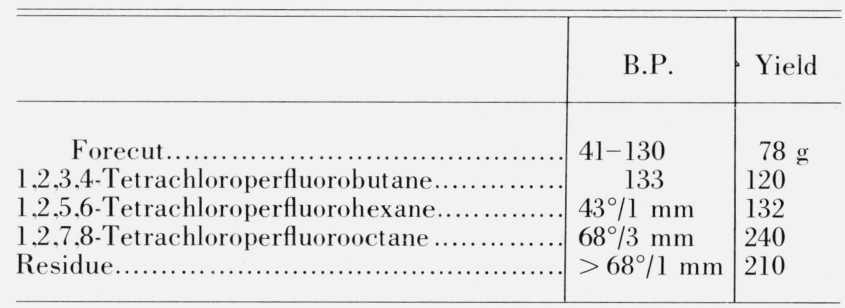

Preparation of 7,8-Dichloroperfluorooctanoic Acid. Thirty g $(0.05 \mathrm{~m})$ of 1,2-dichloro-8-iodoperfluorooctane and $20 \mathrm{ml}$ of 60 percent oleum were placed in a $100 \mathrm{ml}$ steel bomb and the bomb sealed. The bomb was rocked and maintained at $250{ }^{\circ} \mathrm{C}$ for $18 \mathrm{~h}$. The contents were removed from the bomb. The oily organic layer was separated and shaken with aqueous sodium bicarbonate until neutral to $\mathrm{pH}$ paper. The solution was then made acidic with dilute surfuric acid and extracted continuously with ether. The ether extract was dried over anhydrous sodium carbonate and distilled. The yield was $9.4 \mathrm{~g}$ of a colorless oil boiling at $155^{\circ} / 58 \mathrm{~mm}$. This was 38 percent based on the iodooctane used as starting material. On standing the oil slowly solidified. This was consistent with the findings of Knunyants. This acid was later converted to the sodium salt and the salt dried by conventional means.

Preparation of Sodium 7,8-Dichloroperfluorooctanoate. A mixture of $145 \mathrm{~g}(0.25 \mathrm{~m}, 73 \mathrm{ml})$ of 7,8-dichlorol-iodoperfluorooctane and $291 \mathrm{~g}(2.5 \mathrm{~m} 173 \mathrm{ml})$ of chlorosulfonic acid was placed in a glass tube of such size that the tube was about $2 / 3$ full. The tube was placed in a metal bomb surrounded with carbon tetrachloride. The bomb was sealed and placed in a heater. The heater was inclined so that the glass tube was about $85^{\circ}$ from vertical. The bomb and contents were maintained at $146-152^{\circ}$ for $20 \mathrm{~h}$ after which the bomb was permitted to cool to room temperature. The glass tube was removed and cooled to $-196{ }^{\circ} \mathrm{C}$ with liquid nitrogen. It was opened and permitted to warm to room temperature. Warming was accelerated by pouring warm water over the outside of the tube. The contents of the tube was poured on ice cubes. During this step most of the ice melted. On standing an oily layer separated. The aqueous layer was decanted. The oily layer, amounting to $127 \mathrm{~g}$, was added dropwise to a hot solution of $40 \mathrm{~g}(1.0 \mathrm{~m})$ of sodium hydroxide in $500 \mathrm{ml}$ of 
water. After addition heating was continued for two hours. The mixture was then permitted to cool to room temperature and refrigerated overnight. The crystals of 7,8-dichloroperfluorocaprylate were filtered and vacuum dried. The yield was $66 \mathrm{~g}$ or 56.3 percent based on the iodo compound. From the filtrate $35 \mathrm{~g}$ of oil was obtained. This was subjected to infrared analysis and was concluded to be 1,7,8-trichloroperfluoroheptane which Hauptschien suggested to be a byproduct in this type of reaction. The reaction was carried out six times with the yields varying between 44 and 56.5 percent. The product is a white microcrystalline material.

Preparation of 3,4-Dichloropentafluorobutyric Acid. In a 2-liter, 3-neck flask equipped with an efficient stirrer and a long stem thermometer, a mixture of 272 $\mathrm{g}(1.65 \mathrm{~m})$ of potassium permanganate, $350 \mathrm{~g}(4.2 \mathrm{~m})$ of sodium bicaronate, $100 \mathrm{ml}$ of acetone and $400 \mathrm{ml}$ of water was stirred and cooled to $4{ }^{\circ} \mathrm{C}$. To this mixture was added dropwise $284 \mathrm{~g}(1.0 \mathrm{~m})$ of

$$
\mathrm{CCIF}_{2} \mathrm{CCIFCF}_{2} \mathrm{CF}=\mathrm{CF}_{2} .
$$

The latter compound was obtained from the pyrolysis of $\mathrm{CCIF}_{2} \mathrm{CCIFCF}_{2} \mathrm{CFClCF}_{2} \mathrm{COONa}$ in a manner described in earlier work [1]. After addition the mixture was permitted to warm slowly to room temperature, care being exercised to prevent excessive foaming. Excess permanganate was destroyed with 5 percent aqueous sodium bisulphite. Manganese dioxide thus formed w as filtered, washed with water, and discarded. The combined filtrate and washings were clear and colorless. To this was added $160 \mathrm{ml}(294 \mathrm{~g}, 5 \mathrm{~m})$ of 95 percent sulfuric acid. This acid solution was extracted continuously with ether for $50 \mathrm{~h}$. The extract was dried over anhydrous sodium sulphate and distilled. The product was distilled under reduced pressure, yielding $121 \mathrm{~g}$ of a clear, colorless oil boiling at $100{ }^{\circ} \mathrm{C} / 3 \mathrm{~mm}$. This was 49 percent based on the pentene.

Preparation of 3,4-Dichloropentafluorobutyric Acid (Alternative Preparation). Into a 5-liter, 3-neck flask equipped with a condenser arranged for downward distillation was placed $570 \mathrm{~g}(1.5 \mathrm{~m})$ of $\mathrm{CCIF}_{2} \mathrm{CCIFCF}_{2} \mathrm{CF}_{2} \mathrm{I}$ and $2000 \mathrm{~g}$ of 20 percent fuming sulfuric acid. This mixture was heated gently until the acid fluoride,

$$
\mathrm{O}
$$

$\mathrm{CCIF}_{2} \mathrm{CCIFCF}_{2} \mathrm{C}-\mathrm{F}$, began to distill. Heating was then carefully adjusted so that the acid fluoride would continue to distill with a minimum of impurities. Sulfur trioxide which was evolved in copious quantities during the addition was vented from the system through a tube attached to an adapter between the condenser and the receiver. The crude acid fluoride-iodobutane layer, 283 $\mathrm{g}$, was shaken with conc. sulfuric acid in a separatory funnel, removing dissolved sulfur trioxide, then distilled through a column. The yield was $158 \mathrm{~g}$ of

$$
\mathrm{O}
$$

$$
\|
$$

$\mathrm{CCIF}_{2} \mathrm{CCIFCF}_{2} \mathrm{C}-\mathrm{F}$. Approximately $107 \mathrm{~g}$ of butane was recovered. The yield of acid fluoride was 52.3 percent based on the iodobutane which reacted.
The acid fluoride was added dropwise to a solution of $80 \mathrm{~g}$ of sodium hydroxide in $200 \mathrm{ml}$ of water. The mixture was heated to $90{ }^{\circ} \mathrm{C}$ and maintained at this temperature for $30 \mathrm{~min}$. It was cooled and a small amount of oil separated. The aqueous alkali solution was acidified with 50 percent sulfuric acid and extracted continuously with ether for five days. The ether extract was dried over anhydrous sodium sulfate and distilled. The product, 3,4-dichloropentafluorobutyric acid was obtained by distillation under reduced pressure. It amounted to $149 \mathrm{~g}$ of a clear colorless liquid boiling at $100^{\circ} / 3 \mathrm{~mm}$. This was 95 percent based on the acid fluoride or 49.5 percent based on the iodobutane.

Preparation of 3,4-Dichloropentafluorobutyric Acid (2nd Alternative Preparation). In a stainless steel bomb was placed $152 \mathrm{~g}(0.5 \mathrm{~m}, 76 \mathrm{ml})$ of 1,1,3,4,-tetrachlorohexafluorobutane (3M Kel-F Dimer No. 464) $72 \mathrm{ml}$ of conc. sulfuric acid and $34 \mathrm{ml}$ of 30 percent fuming sulfuric acid. The bomb was sealed. It was rocked, heated to $200{ }^{\circ} \mathrm{C}$ and maintained at this temperature for $96 \mathrm{~h}$. It was cooled to $-80^{\circ} \mathrm{C}$, opened and permitted to warm to room temperature. Intense foaming and evolution of gas occurred, but the contents of the bombs were successfully transferred to a beaker. On standing, the foaming and gas evolution subsided. This mixture was distilled under reduced pressure yielding $65 \mathrm{~g}$ of clear liquid boiling at $61^{\circ} / 1 \mathrm{~mm}$ or 53 percent based on the butane. It gave the same index of refraction as samples prepared in the other two ways. $\mathrm{N}_{\mathrm{D}}^{20}$ 1.3470 .

Preparation of 3-Chloropentafluoropropene. Fifty grams $(0.21 \mathrm{~m})$ of 3,4-dichloropentafluorobutyric acid were converted to the sodium salt by neutralizing an aqueous solution of the acid with sodium hydroxide so that the resulting solution had a $\mathrm{pH}$ of 7 . This was evaporated to absolute dryness in a vacuum desiccator, yielding $56 \mathrm{~g}$ of anhydrous sodium 3,4-dichloropentafluorobutyrate. The salt was pyrolyzed in a $250 \mathrm{ml}$ round-bottom flask which was connected by adapters to three liquid nitrogen-cooled traps connected in tandem. Heat was supplied by a microburner. The yield was $32 \mathrm{~g}$ or 91.5 percent based on the acid salt. This was distilled through a column packed with glass helices. The yield of pure compound was $30 \mathrm{~g}$ or 86.2 percent. B:P. $8{ }^{\circ} \mathrm{C}$.

Preparation of Pentafluoro 3-Iodopropene. A 2-liter, 3-nerk flask was equipped with a stirrer, a thermometer, and a reflux condenser topped by a dry ice acetone-cooled cold finger type condenser topped by a calcium chloride drying tube. Into the flask was placed $83 \mathrm{~g}(0.6 \mathrm{~m})$ of sodium iodide and $300 \mathrm{ml}$ of freshly distilled methyl-ethyl ketone. Stirring was commenced and into the flask was distilled $58 \mathrm{~g}(0.35 \mathrm{~m})$ of 3 chloropentafluoropropene. The mixture was refluxed for $24 \mathrm{~h}$. The reflux temperature rose from 20 to $60{ }^{\circ} \mathrm{C}$. The product was removed from the flask, filtered, and the filtrate distilled. A fraction boiling between $50^{\circ}$ and $55^{\circ}$ was collected and redistilled through a 10 -in column packed with glass helices. The yield was $40 \mathrm{~g}$ of a clear colorless liquid which slowly turned violet on standing. This was 44.2 percent based on the chloropentafluoropropene. B.P. $53{ }^{\circ} \mathrm{C}$. 
Preparation of 1,2-Dichloro-pentafluoro 3-iodopropane. Seventy-four g $(0.3 \mathrm{~m})$ of 3,4-dichloropentafluorobutyric acid was carefully neutralized with $3.5 \mathrm{~N}$ ammonium hydroxide. To the solution was added a solution of $60 \mathrm{~g}$ of silver nitrate in $200 \mathrm{ml}$ of water. Upon refrigeration, silver 3,4-dichloropentafluorobutyrate crystallized and was filtered. Concentration of the filtrate produced additional product. The salt was dried in a vacuum oven at $60{ }^{\circ} \mathrm{C}$ for a week. The yield was $104 \mathrm{~g}$ or 99 percent.

Seventy g $(0.2 \mathrm{~m})$ of powdered silver 3,4-dichloropentafluorobutyrate was mixed with $76 \mathrm{~g}(0.3 \mathrm{~m})$ of powdered iodine. The mixture was sifted until homogeneous. It was placed in a metal tube attached to two dry ice acetone-cooled traps and a bubble counter in series. The silver salt-iodine mixture was pyrolyzed by heat from a micro burner, beginning with the end nearest the traps and keeping the evolution of carbon dioxide fairly constant as indicated by the bubble counter. The product was obtained from the first trap. It amounted to $16 \mathrm{~g}$ or 24 percent. The crude product was distilled through a 6 -in column packed with glass helices. The yield of pure 1,2-dichloro-3-iodopentafluoropropane was $10 \mathrm{~g}$ or 15 percent based on the butyric acid. B.P. $119^{\circ} \mathrm{C}$. The predominant yield was 3 -chloropentafluoropropene, the product described above in the pyrolysis of sodium 3,4-dichloropentafluorobutyrate.

Analysis of $\mathrm{C}_{3} \mathrm{ClF}_{5} \mathrm{I}$

$\begin{array}{lccc} & \text { C } & \text { Cl } & \text { I } \\ \text { Calculated ...... } & 10.9 & 21.8 & 38.4 \\ \text { Found............ } & 11.2 & 22.5 & 38.0\end{array}$

Preparation of 5,6-Dichloroperfluorohexanoic Acid. In an 800-ml stainless steel bomb a mixture of $478 \mathrm{~g}$ $(1.0 \mathrm{~m})$ of 1,2-dichloro-6-iodoperfluorohexane and $654 \mathrm{~g}$ $(5.6 \mathrm{~m})$ of chlorosulfonic acid was rocked and heated to $150^{\circ} \mathrm{C}$. It was maintained at this temperature with rocking for $72 \mathrm{~h}$. The liquid was removed from the bomb and added dropwise to $3000 \mathrm{ml}$ of water in a beaker. The bomb was washed with two $500-\mathrm{ml}$ portions of water and the washings were added to the beaker. An oil slowly separated. The aqueous layer was decanted. The oil was transferred to a separatory funnel diluted to three times it original volume with ether and washed with three $200-\mathrm{ml}$ portions of water. The ether solution was dried over anhydrous sodium sulfate and distilled. The product was obtained by distillation under reduced pressure. It amounted to $254 \mathrm{~g}$ of a clear colorless liquid boiling at $138{ }^{\circ} \mathrm{C} / 63 \mathrm{~mm}$. This acid had the same index of refraction, $\mathrm{N}_{\mathrm{D}}^{20} 1.3612$, reported by Knunyants. The percentage yield was 73.5.

Preparation of 1,2-Dichloro-perfluoro 5-iodopentane. Thirty-eight $\mathrm{g}(0.11 \mathrm{~m})$ of 5,6-dichloroperfluorocaproic acid was converted to the dry silver salt in the manner described above for 3,4-dichloropentafluorobutyric acid and pyrolyzed in the presence of a 100 percent molar excess of powdered iodine in a stainless steel tube attached through on an adapter to a large flask which was attached to a dry ice acetone-cooled trap and a vacuum pump. The pyrolysis was carried out under reduced pressure. Total pyrolysis products amounted to $40 \mathrm{~g}$. This material was distilled through a column under reduced pressure. Yield of the iodopentane was $21 \mathrm{~g}$ or 44.5 percent based on the caproic acid. B.P. $68^{\circ} / 40 \mathrm{~mm}$. There was a large solid residue.

Analysis for $\mathrm{C}_{5} \mathrm{~F}_{9} \mathrm{Cl}_{2} \mathrm{I}$

$\begin{array}{lccc} & \text { C } & \text { Cl } & \text { I } \\ \text { Calculated ...... } & 14.0 & 16.6 & 29.6 \\ \text { Found ........... } & 14.2 & 15.9 & 28.9\end{array}$

Preparation of 5,6-Dichloroperfluoro-1-hexene. A 2liter resin flask was equipped with a stirrer, reflux condenser and a dropping funnel. It was evacuated and the wall thoroughly dehydrated by heating while a vacuum was maintained in the flask. Dry nitrogen was admitted to the flask and a slow nitrogen flow was maintained throughout the reaction. Into the flask was poured $240 \mathrm{~g}(0.5 \mathrm{~m})$ of 5,6-dichloro-1-iodoperfluorohexane and $1000 \mathrm{ml}$ of carefully dried ether. This was cooled to $-80{ }^{\circ} \mathrm{C}$ with a dry ice acetone bath. With vigorous stirring a solution of $12 \mathrm{~g}(0.55 \mathrm{~m})$ of methyl lithium was added dropwise. Stirring was continued and the reactants were permitted to warm to room temperature. To the mixture was added $200 \mathrm{ml}$ of water followed by $200 \mathrm{ml}$ of 20 percent hydrochloric acid. Stirring was continued for $2 \mathrm{~h}$. The mixture was transferred to a separatory funnel; the aqueous layer was separated and discarded. The ether solution was dried over anhydrous sodium sulphate and distilled. Seventy grams of starting material was recovered. The yield was $80 \mathrm{~g}$ or 68 percent based on the hexane which reacted. B.P. $116^{\circ} \mathrm{C}$. Also obtained was $8.5 \mathrm{~g}$ of material boiling at $143^{\circ}$, which was not characterized and a small solid residue.

Preparation of Perfluoro 1,1,7-trihydroheptane. A 1400-ml silver lined bomb was charged with $498 \mathrm{~g}$ $(1.5 \mathrm{~m})$ of 1,1,7-trihydroperfluoroheptanol (Dupont fluoroalcohol C7) and sealed. Through copper tubing $256 \mathrm{~g}(238 \mathrm{~m})$ of sulfur tetrafluoride was poured directly into the bomb from a cylinder as the bomb rested on a balance. The cylinder was gently heated to facilitate the transfer. A heater-rocker apparatus was heated to $100{ }^{\circ} \mathrm{C}$. The bomb was placed in it and rocked. Heating was discontinued, but the temperature rose to $130^{\circ}$, then slowly subsided. Heating was resumed. The bomb was maintained at $100^{\circ} \mathrm{C}$ for $4 \mathrm{~h}$. Heating was again discontinued but the bomb was permitted to rock for an additional $18 \mathrm{~h}$. When the bomb had cooled the gaseous contents were vented through a solution of $550 \mathrm{~g}$ of sodium hydroxide in $4000 \mathrm{ml}$ of water, thus removing thionyl fluoride, hydrogen fluoride and excess sulfur tetrafluoride. Dry nitrogen was passed through the bomb in a further effort to remove corrosive gases. The bomb was opened. From a beaker $500 \mathrm{ml}$ of cold potassium hydroxide solution was cautiously added to the bomb. The mixture was stirred manually until there was no further odor of sulfur tetrafluoride. The bomb contents were transferred to a $1500 \mathrm{ml}$ beaker. The aqueous layer was decanted. The oily layer was washed with two $250 \mathrm{ml}$ portions of cold water, then dried over anhydrous sodium sulfate and distilled 
through an 18-in column packed with glass helices. In all $128 \mathrm{~g}$ of starting material was recovered. Yield of product was $272 \mathrm{~g}$ or 73 percent based on the telomer alcohol which reacted. B.P. $123-4^{\circ}$.

Analysis of $\mathrm{C}_{7} \mathrm{~F}_{13} \mathrm{H}_{3}$

$\begin{array}{cccc} & \text { C } & \text { F } & \text { H } \\ \text { Calculated ...... } & 25.1 & 74.0 & 0.9 \\ \text { Found........... } & 25.2 & 73.7 & 0.8\end{array}$

Preparation of Perfluoro 7-Hydroheptaldehyde. A 500 -ml 3-neck flask was equipped with a dropping funnel, an 18-in column packed with glass helices and a still head. Into the flask was placed $83 \mathrm{~g}(0.25 \mathrm{~m})$ of 1,1,7-hydroperfluoroheptanol (Dupont fluoroalcohol C7). This alcohol was heated until it boiled vigorously but did not distill through the column. A solution of $26 \mathrm{~g}(0.1 \mathrm{~m})$ of sodium dichromate and $35 \mathrm{~g}(0.35 \mathrm{~m})$ of sulfuric acid in $150 \mathrm{ml}$ of water was added slowly through the funnel. 7-Hydroperfluoroheptaldehyde and water distilled through the column into the receiver forming two phases. The water layer was separated and extracted with three $100 \mathrm{ml}$ portions of ether. The ether extracts were combined and added to the free aldehyde. The ether solution was dried over sodium sulfate and distilled. The fraction boiling at 121 to $122{ }^{\circ} \mathrm{C}$ was retained as the product. Higher boiling fractions were retained separately but not characterized further. The yield was $58 \mathrm{~g}$ or 70 percent. Upon standing in air the aldehyde slowly forms a monohydrate.

Preparation of Perfluoro 1,7-Dihydroheptane. An $800-\mathrm{ml}$ stainless steel bomb was charged with $349 \mathrm{~g}$ $(1.0 \mathrm{~m})$ of 7-hydroperfluoroheptaldehyde-monohydrate. Through a valve attached to the bomb $275 \mathrm{~g}(2.5 \mathrm{~m})$ of sulphur tetrafluoride was poured into the bomb from a measuring device. The bomb was rocked, heated to $150{ }^{\circ} \mathrm{C}$ and maintained at that temperature for $68 \mathrm{~h}$. It was cooled to room temperature and the excess sulphur tetrafluoride was permitted to bubble through a large flask containing potassium hydroxide solution. The contents of the bomb were removed, treated with sodium fluoride and sodium sulphate, then filtered. The filtrate was distilled. A fraction boiling at 110 to $112{ }^{\circ} \mathrm{C}$ was retained as the product. This amounted to $15 \mathrm{~g}$ or 4.3 percent based on the aldehyde hydrate.

Analysis of $\mathrm{C}_{7} \mathrm{~F}_{14} \mathrm{H}_{2}$.

$\begin{array}{lccc} & \text { C } & \text { H } & \text { F } \\ \text { Calculated ...... } & 23.9 & 0.9 & 75.5 \\ \text { Found........... } & 23.8 & 0.6 & 75.3\end{array}$

Attempted Preparations of Perfluoro-1,6-Heptadiene. In a $100-\mathrm{ml}$ flask a mixture of $7 \mathrm{~g}(0.02 \mathrm{~m}) \mathrm{H}\left(\mathrm{CF}_{2}\right)_{7} \mathrm{H}$. $2.3 \mathrm{~g}(0.04 \mathrm{~m})$ of potassium hydroxide, and $50 \mathrm{ml}$ of absolute alcohol was refluxed for five days. The components were separated and the starting material recovered unchanged.

In a $75-\mathrm{ml}$ flask a mixture of $7 \mathrm{~g}(0.02 \mathrm{~m})$ of $\mathrm{H}\left(\mathrm{CF}_{2}\right)_{7} \mathrm{H}$ and $2.3 \mathrm{~g}(0.04 \mathrm{~m})$ of potassium hydroxide was refluxed for $24 \mathrm{~h}$. The mixture turned brown and the potassium hydroxide became coated with a dark substance. Five $\mathrm{g}$ of the heptane were recovered but no product was obtained.

Small amounts of 1,7-dihydroperfluoroheptane were put through steel tubes packed with (1) sodium fluoride, (2) steel wool, (3) nickel turnings. (4) platinum on carbon. This work was carried out under vacuum and under an atmosphere of dry nitrogen and at temperatures ranging between 300 and $600{ }^{\circ} \mathrm{C}$ at $50^{\circ}$ intervals. Below $550{ }^{\circ} \mathrm{C}$ starting material was recovered unchanged. At $600^{\circ}$ and above extensive carbonization occurred. Very little of the heptane was recovered and no unsaturated products were obtained under any combination of conditions.

Preparation of Perfluoro-1,7-octadiene. A 2-liter, 3 -neck flask was equipped with a dropping funnel, an efficient stirrer and a still head. Into it was placed $134 \mathrm{~g}(2 \mathrm{~m})$ of powdered zinc and $1000 \mathrm{ml}$ of bis[2[(2methoxy-ethoxy)ethyl] ether. This suspension was heated to $120{ }^{\circ} \mathrm{C}$ and maintained at this temperature. To it was added dropwise $504 \mathrm{~g}(1 \mathrm{~m})$ of 1,2,7,8-tetrachloroperfluorooctane. Perfluoro-1,7-octadiene distilled at approximately the same rate as the octane was added after a short incubation period. The crude product was distilled through a 10 -in column packed with glass helices. A clear colorless liquid boiling at $106^{\circ} \mathrm{C}$ was obtained. The yield was $240 \mathrm{~g}$ or 66.5 percent based on the tetrachloroperfluorooctane.

Preparation of Perfluoro-1,5-hexadiene (Miller's Method) or (Method No. 1). In a 100-ml 3-neck flask equipped with a stirrer and reflux condenser was placed $5 \mathrm{~g}(0.077 \mathrm{~m})$ of activated zinc suspended in $30 \mathrm{ml}$ of carefully dried dioxane. The opening of the condenser was connected to a dry ice acetone-cooled trap. The apparatus was swept out with dry nitrogen. While stirring briskly, $14.1 \mathrm{~g}(0.055 \mathrm{~m})$ of 3 -iodopentafluoropropene (perfluoroallyl iodide) was added dropwise over a period of $1 \mathrm{~h}$. After addition the contents of the flask were refluxed for $4 \mathrm{~h}$ and permitted to stand at room temperature for $68 \mathrm{~h}$. The crude hexadiene was distilled directly from the flask. Distillate was collected up to $100{ }^{\circ} \mathrm{C}$ then distilled through a 10-in glass column packed with glass helices. The product was $4 \mathrm{~g}$ of clear colorless liquid boiling at $59{ }^{\circ} \mathrm{C}$ or 55.5 percent based on the 3 -iodopentafluoropropene.

Preparation of Perfluoro-1,5-hexadiene (Knunyant's Method) or (Method No. 2). A 1-liter flask was equipped with a stirrer, a still head, and a dropping funnel. Into it was placed $52 \mathrm{~g}(0.8 \mathrm{~m})$ of zinc powder, $360 \mathrm{ml}$ of acetic acid and $90 \mathrm{ml}$ of acetic anhydride. This mixture was stirred and heated to gentle reflux. Heating was discontinued and to the stirred suspension was added $73 \mathrm{~g}(0.18 \mathrm{~m})$ of 1,2,5,6-tetrachloroperfluorohexane at a rate such that perfluorohexadiene distilled as rapidly as it formed. The crude hexadiene was distilled through a 10-in glass column packed with glass helices to produce $26 \mathrm{~g}(0.099 \mathrm{~m})$ of clear colorless liquid boiling at $59^{\circ} \mathrm{C}$. This was 55 percent based on the hexane.

The acetic acid solution was poured into $3000 \mathrm{ml}$ of water. Twenty-four $g$ of fluorocarbon separated. This material was dried and distilled yielding $15 \mathrm{~g}(0.045 \mathrm{~m})$ of material boiling at $115^{\circ} \mathrm{C}$ which was assumed to be 
either 5,6-dichloroperfluoro-1-hexene or 6,6-dichloroperfluoro-1-hexene and $8 \mathrm{~g}(0.02 \mathrm{~m})$ of liquid boiling at $43^{\circ} / 1 \mathrm{~mm}$ or at $171^{\circ}$ at atmospheric pressure. This was considered to be either 1,2,5,6-tetrachloroperfluorohexane or 1,1,6,6-tetrachloroperfluorohexane. 6,6-Dichloroperfluoro-1-hexene, and 1,1,6,6-tetrachloroperfluorohexane would arise from an isomeric impurity produced in the preparation of 1,2-dichloro-1-iodotrifluoroethane.

Preparation of Perfluoro-1,5-hexadiene (FearnBrown Method or Method No. 3). A 1-liter 3-neck flask was fitted with a stirrer, still head and dropping funnel as described above. Into it was placed $26 \mathrm{~g}(0.4 \mathrm{~m})$ of powdered zinc, $360 \mathrm{ml}$ of acetic acid and $90 \mathrm{ml}$ of acetic anhydride. The mixture was stirred and heated to reflux. Heating was discontinued and $67 \mathrm{~g}(0.2 \mathrm{~m})$ of 5,6-dichloroperfluoro-1-hexene was added dropwise. Perfluoro-1.5-hexadiene distilled at the same rate. The crude product was washed three times with cold dilute sodium carbonate solution, then three times with cold water. It was dried over anhydrous sodium sulfate and distilled. The yield was $34 \mathrm{~g}$ of clear colorless liquid boiling at 59 to $60{ }^{\circ} \mathrm{C}$ or 65 percent based on the dichloroperfluorohexene.

Preparation of Perfluoro-1,6-heptadiene (Method No. 1). Into a 1-liter 3-neck flask fitted with a stirrer. a reflux condenser, and a dropping funnel was placed a mixture of $13.1 \mathrm{~g}(0.2 \mathrm{~m})$ of zinc powder, $400 \mathrm{ml}$ of methylene chloride and $160 \mathrm{ml}$ of acetic anhydride. The mixture was stirred and heated to reflux. To it was added dropwise a mixture of $19.3 \mathrm{~g}(0.045 \mathrm{~m})$ of 1,2-dichloro-5-iodopentane and $55.9 \mathrm{~g}(0.2 \mathrm{~m})$ of 1,2-dichloro-1-iodotrifluoroethane. After addition the mixture was stirred and refluxed for $24 \mathrm{~h}$. The mixture was filtered and the filtrate added slowly to $4000 \mathrm{ml}$ of cold water in a beaker. This mixture was stirred vigorously for $4 \mathrm{~h}$. The organic layer was separated, dried, and distilled. The yields are recorded below.

(1) 1,2,3,4-Tetrachloroper-

B.P. Gms fluorobutane........... $133^{\circ} \quad 16.8$

(2) 1,2,6,7-Tetrachloroperfluoroheptane........... $74 / 19 \mathrm{~mm} \quad 7.9$

(3) 1,2,9,10-Tetrachloroperfluorodecane........... $94 / 5 \mathrm{~mm} \quad 6.0$

Compounds 1 and 3 are known.

Analysis for Compound $2 \mathrm{C}_{7} \mathrm{~F}_{12} \mathrm{Cl}_{14}$

$\begin{array}{lcc} & \text { C } & \text { Cl } \\ \text { Calculated ...... } & 18.5 & 31.3 \\ \text { Found.......... } & 18.4 & 30.9\end{array}$

Compound 2 was dehalogenated in the manner described above for perfluorooctadiene. Seven grams $(0.015 \mathrm{~m})$ of 1,2,6,7-tetrachloroperfluoroheptane yielded $3.5 \mathrm{~g}(0.011 \mathrm{~m})$ of perfluoro-1,6-heptadiene or 75.5 percent based on the heptane. B.P. $86^{\circ} \mathrm{C}$.

Preparation of Perfluoro-1,6-heptadiene (Method No. 2). Into a 500-ml 3-neck flask fitted with a stirrer, a reflux condenser and a dropping funnel was placed a mixture of $6.5 \mathrm{~g}(0.1 \mathrm{~m})$ of zinc powder, $200 \mathrm{ml}$ of methylene chloride and $80 \mathrm{ml}$ of acetic anhydride. The mixture was stirred and heated to gentle reflux. To it was added dropwise a mixture of $9 \mathrm{~g}(0.027 \mathrm{~m})$ of 1,2 dichloro-3-iodopropane and $21 \mathrm{~g}(0.055 \mathrm{~m})$ of $1,2-$ dichloro-4-iodobutane. After addition the mxiture vas stirred and refluxed for $15 \mathrm{~h}$. The mixture was filtered and the filtrate added to $2000 \mathrm{ml}$ of water in a beaker. The mixture was stirred vigorously for $4 \mathrm{~h}$. The organic layer was separated, dried, and distilled. Yields are recorded below.

B.P. Gms

(1) 1,2,5,6-Tetrachloroperfluorohexane............

(2) 1,2,6,7-Tetrachloroperfluoroheptane...........

(3) 1,2,7,8-Tetrachloroperfluorooctane............ $68 \% 1 \mathrm{~mm}$

$74 \% 19 \mathrm{~mm}$

Compound 2 was again dehalogenated as described above. Five $\mathrm{g}(0.011 \mathrm{~m})$ of 1,2,6,7-tetrachloroperfluoroheptane yielded $2.7 \mathrm{~g}(0.0087 \mathrm{~m})$ of perfluoro-1,6heptadiene or 79 percent. B.P. $86^{\circ} \mathrm{C}$.

Preparation of Perfluoro-1,6-heptadiene (Method No. 3). In a metal tube attached to two dry ice acetonecooled traps connected in series and finally to a vacuum pump, $328 \mathrm{~g}(0.68 \mathrm{~m})$ of sodium 6,7-dichloroperfluorocaprylate was pyrolyzed. Heat was applied by a cylindrical furnace surrounding the metal tube. Pyrolysis was carried out at $380{ }^{\circ} \mathrm{C}$ as indicated by a pyrometer. The product, crude 6,7-dichloroperfluoro-1heptene was dried over anhydrous sodium sulfate and distilled through an 18-in column packed with glass helices under an atmosphere of dry nitrogen. The yield was $220 \mathrm{~g}$ or 84.5 percent based on the sodium salt. B.P. $138^{\circ} \mathrm{C}$.

Analysis for $\mathrm{C}_{7} \mathrm{Cl}_{2} \mathrm{~F}_{12}$

$\begin{array}{lcc} & \mathrm{C} & \mathrm{Cl} \\ \text { Calculated ....... } & 21.9 & 18.5 \\ \text { Found........... } & 21.8 & 18.4\end{array}$

In a 1000-ml 3-neck flask equipped with a stirrer, dropping funnel and still head, a mixture of $26 \mathrm{~g}(0.4 \mathrm{~m})$ of zinc powder which had been previously activated by treatment with conc. hydrochloric acid in acetone and $500 \mathrm{ml}$ of bis [2-(2-methoxyethoxy)ethyl] ether was stirred and heated to $75^{\circ} \mathrm{C}$. To this suspension was added dropwise $76.6 \mathrm{~g}(0.2 \mathrm{~m})$ of 6.7-dichoroperfluoro-1-hexene. After a brief incubation period, perfluoro-1,6-heptadiene began to distill at the same rate as the hexene was added. The crude diene was treated with phosphorus pentoxide, filtered, then distilled under an atmosphere of dry nitrogen through a 10 -in column packed with glass helices. The yield was $48 \mathrm{~g}(0.154 \mathrm{~m})$ or 76 percent based on the heptene. B.P. $86^{\circ}$. Nine g of residue boiling above $90^{\circ} \mathrm{C}$ was obtained but not studied. 
Analysis for $\mathrm{C}_{7} \mathrm{~F}_{12}$

C

Calculated ...... $\quad 26.9$

Found........... 26.7

\section{Discussion}

\subsection{Synthesis}

The ethanes other than $\mathrm{CF}_{2}$ ClCFClI mentioned in the introduction were prepared as follows:

1. $\mathrm{CF}_{2} \mathrm{CF}_{2}+\mathrm{ICl} \longrightarrow \mathrm{CF}_{2} \mathrm{ClCF}_{2} \mathrm{I}$

2. $\mathrm{CF}_{2} \mathrm{CF}_{2}+\mathrm{I}_{2} \stackrel{\mathrm{CF}_{2} \mathrm{Br}_{2}}{\longrightarrow} \mathrm{CF}_{2} \mathrm{ICF}_{2} \mathrm{I}$

3. $\mathrm{CF}_{2} \mathrm{CFH}+\mathrm{ICl} \longrightarrow \mathrm{CF}_{2} \mathrm{ClCFHI}$.

All three addition reactions took place readily, giving yields which were virtually quantitative. Efforts to telomerize these materials with tetrafluoroethylene in the manner described above were abortive. 1-chlorotetrafluoroethane-2-iodo does not add tetrafluoroethylene to form a telomer nearly as readily as tetrafluoroethylene homopolymerizes. As a result efforts to carry out the reaction

\section{$\mathrm{CF}_{2} \mathrm{ClCF}{ }_{2} \mathrm{I}+\mathrm{CF}_{2} \mathrm{CF}_{2} \longrightarrow \mathrm{CF}_{2} \mathrm{ClCF}_{2}\left(\mathrm{CF}_{2} \mathrm{CF}_{2}\right)_{n} \mathrm{I}$}

resulted chiefly in the preparation of high polymer with only traces of liquid products. Attempts to telomerize 1-chloro-1,1,2-trifluoroethane-2 iodo with tetrafluoroethylene were even less successful, yielding only high polymer. If the telomers had formed the former would have proved very difficult to dechlorofluorinate but dehydrochlorination of the latter would have been feasible. The reaction $\mathrm{ICF}_{2} \mathrm{CF}_{2} \mathrm{I}+\mathrm{CF}_{2} \mathrm{CF}_{2} \longrightarrow \mathrm{I}\left(\mathrm{CF}_{2} \mathrm{CF}_{2}\right)_{n} \mathrm{I}$ was found to take place but Knunyants [14] asserted that this is not a telomerization but a coupling process which takes place according to the following mechanism.

$$
\begin{aligned}
& \mathrm{ICF}_{2} \mathrm{CF}_{2} \mathrm{I} \stackrel{250{ }^{\circ} \mathrm{C}}{\longrightarrow} \mathrm{ICF}_{2} \mathrm{CF}_{2}^{*}+\mathrm{I}^{*} \\
& 2 \mathrm{ICF}_{2} \mathrm{CF}_{2}^{*} \longrightarrow \mathrm{I}\left(\mathrm{CF}_{2} \mathrm{CF}_{2}\right)_{2} \mathrm{I} \\
& 2 \mathrm{I} \mathrm{I}_{2} \longrightarrow \mathrm{I}_{2}
\end{aligned}
$$

The diiodobutane may then loose an iodine atom to form a radical which may couple with another iodobutyl radical or an iodoethyl radical to produce, respectively, a diiodooctane or a diodohexane. The stability of the molecule increases with the number of carbon atoms between the terminal iodines. The findings in all of this work tend to enhance the view that $\mathrm{R}-\mathrm{CF}_{2} \mathrm{I}$ type compounds do not form radicals which either couple or initiate polymerization nearly as readily as $\mathrm{R}$-CFClI type structures. The telomerization of $\mathrm{CF}_{2} \mathrm{ClCFClI}$ with tetrafluoroethylene proceeded with gamma initiation in the same manner as Knunyants obtained using benzoyl peroxide catalysis $[10]$.
The yields of perfluorohexadiene were acceptable in all three syntheses, the last preparation being superior in overall efficiency. The deiodofluorination reaction employing methyl lithium is a subject for further study since the exact conditions under which lithium fluoride splits out have not been precisely established. As of this writing efforts to prepare perfluoro-1,5hexadiene by double deiodofluorination of $\mathrm{I}\left(\mathrm{CF}_{2} \mathrm{CF}_{2}\right)_{3} \mathrm{I}$ are continuing. Dechlorinations were in all cases routine.

Difficulties with the first proposed synthesis of perfluoro-1,6-heptadiene were discussed above. In the second effort the weakest link was the cross coupling reaction. The 1,2-dichloro-1-iodotrifluoroethane tends to homocouple for reasons indicated above. Another factor is the possibility of telomerizing the iodohexane used in preparing the iodopentane with tetrafluoroethylene to produce the iodooctane which is the starting material in the preferred synthesis. The hang-up in the third proposed synthesis is the pitifully small yield of 1,2-dichloro-3-iodopentafluoropropane in the mixed pyrolysis of silver 3,4-dichloropentafluorobutyrate and iodine. This results from the partial distillation of iodine from the reaction chamber before the pyrolysis temperature is reached. In this synthesis the cross coupling reaction proved reasonably efficacious. The fourth synthesis produced a quandry. The telomer obtained from 1,2-dichloro-4-iodobutane and hexafluoropropylene formed in good yield through the reaction scheme shown in the introduction. The deiodofluorination reaction, which was carried out experimentally in the manner described above for 5.6-dichloroperfluoro-1-hexane produced a multiplicity of compounds. These were separated on a preparative scale vapor phase chromatograph (VPC) and one of the major components was identified by analytical VPC and infrared studies as the desired 6,7-dichloroperfluoro-1-heptene. Evidence suggested strongly that another was 6,7-dichloroperfluoro-2-heptene. With the l-heptene the VPC retention time and the infrared spectrum of the sample obtained was identical with that of a sample of this compound prepared in the manner described below. With the 2-heptene the retention time was slightly lower and the peak in the infrared spectrum usually associated with the double bond was displaced from $5.6 \mu$ to $5.4 \mu$, the usual displacement between a terminal and an internal double bond. The mechanism through which each of these fluoroolefins is formed is illustrated below.

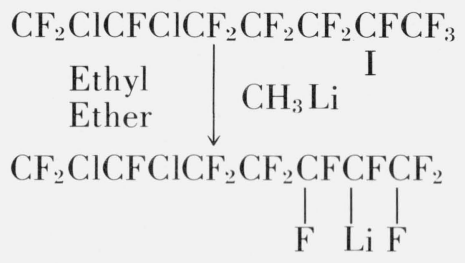

If the lithium atom splits out with a fluorine atom from the terminal carbon atom the 1-heptene results, but if it selects a fluorine atom from the adjacent internal carbon atom the 2-heptene is produced. Results indi- 
cate a competition between these two processes. A third component, whose infrared spectrum suggested a saturated compound was considered to be cyclic, possibly

\section{$\mathrm{CF}_{2} \mathrm{ClCFClCFCF}_{2} \mathrm{CF}_{2} \mathrm{CFCF}_{3}$}

The fact that this substance will undergo dechlorination militates against the five-member ring that one would expect. If the lithium atom attacked either the terminal or the penultimate carbon atom one would expect the chlorine atom to split off much easier than the fluorine atom, producing a compound which would not undergo intramolecular dechlorination as this compound does. The structure above remains a postulation since neither infrared, nuclear magnetic resonance $\left({ }^{19} \mathrm{~F}\right)$ nor any other technique provided conclusive proof. The problem of separating the many products made this an unacceptable preparation for perfluoro-1,6-heptadiene. A possible explanation for the occurrence of some of these products many of which were not identificable by black box technique lay in the possibility that the initial telomerization reaction produced some head-to-head addition rather than uniformly head-to-tail addition predicted by the work of Hauptschein [15] on similar compounds, e.g.,

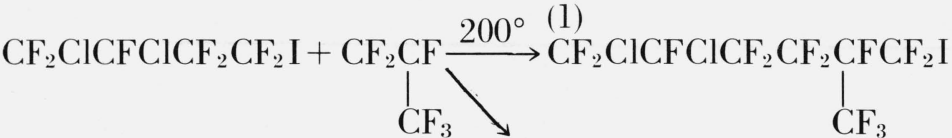

$$
\begin{aligned}
& \text { (2) } \\
& \mathrm{CF}_{2} \mathrm{ClCFClCF}_{2} \mathrm{CF}_{2} \mathrm{CF}_{2} \mathrm{CFI} \\
& \mathrm{CF}_{3}
\end{aligned}
$$

Deiodofluorination can then give rise to a compound with the formula $\mathrm{CF}_{2} \mathrm{ClCFClCF}_{2} \mathrm{CF}_{2} \mathrm{CFCF}_{2}$ which $\mathrm{CF}_{3}$ could not occur through a uniform head-to-tail telomerization. In the presence of fluoridation the double bond of this compound could consequently move inward, i.e.,

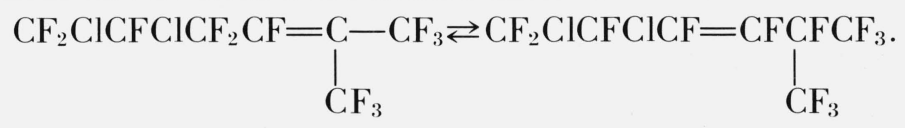

In this way one head-to-head addition could result in three additional compounds.

The methods and principles employed in these investigations may be utilized in preparing any fluorodiene between perfluorobutadiene through $\mathrm{CF}_{2} \mathrm{CF}\left(\mathrm{CF}_{2}\right)_{16} \mathrm{CFCF}_{2}$. Terminal fluorodienes with more than eight carbon atoms are not suitable for the interintramolecular polymerization studies that provided the impetus for undertaking these syntheses. Perfluoro1,8-nonadiene may be prepared from 1,2-dichloro-10iodoperfluorodecane in the manner described in the fifth synthesis of perfluoro-1,6-heptadiene. In the same manner any perfluorodiene with an odd number of carbon atoms may be prepared from a telomer with one more carbon atom than the desired diene. All of the even numbered dienes may be prepared by crosscoupling and dechlorinating selected telomers. Telomers containing 12 carbon atoms or more are solid and virtually impossible to distill or selectively sublime. This makes the preparation of fluorodienes of 24 carbon atoms or more somewhat more difficult according to methods discussed above. Their preparation would involve the development of a sophisticated separation for the higher telomers.

\subsection{Chemistry}

Since perfluoropentadiene and 4-chloroperfluoro-1,6heptadiene did not yield polymer of significant molecular weight except when polymerized at high pressure
$[1,2,3]$, no studies were made of perfluorodienes containing 6,7 , or 8 carbon atoms at pressures less than $5000 \mathrm{~atm}$. Often at these pressures crystallization of monomer will occur. As this can greatly affect the nature of the polymerization reaction it is desirable to know the freezing pressure. This crystallization was detected by careful observation of isobaric volume changes during application of pressure [16]. Plotting the pressure at which isobaric volume changes occurred against temperature produced curves similar in slope for perfluoropentadiene and for perfluoro-1,7octadiene, suggesting that perfluoro-1,5-hexadiene will show a similar slope when polymerization studies on it are completed. Perfluoro-1,6-heptadiene increased in viscosity during the application of pressure but showed no isobaric volume change, indicating that no freezing took place at $22^{\circ}$ at even $10000 \mathrm{~atm}$. The observed freezing temperatures were not found to vary monotonically with the number of carbon atoms in the compound but this is not unusual. Even with linear alkanes the pattern of variation is often complex.

Polymerization techniques did not differ from those previously described [17]. Initiation was effected by radiation from a ${ }^{60} \mathrm{Co}$ source. Preliminary investigations were carried out in bulk. The kinetic chain length was computed in the following fashion. At $0.045 \mathrm{Mrad} / \mathrm{h}$ about $5 \times 10^{-3}$ percent per hour of the monomer was converted to initiating species, presumably radicals, if the $G$ value (yield per $100 \mathrm{eV}$ ) for initiation is four. The kinetic chain length was taken as the ratio of the 
percent of polymer formed to $5 \times 10^{-3}$ times the irradiation time. For the purpose of these investigations this approximation is valid and sufficient. The ratio of polymerized monomer units to the number of perfluorovinyl groups in the polymer was obtained by a Beer's law computation from data obtained from infrared spectra. This type of computation proved very useful in earlier work [2,3]. With perfluorohexadiene and perfluorooctadiene polymers these values are thought to have an uncertainty factor of about 2 . With perfluoro1,6-heptadiene polymer its crystallinity makes the accuracy of the $\mathrm{C}_{n} \mathrm{~F}_{2 n-2} / \mathrm{CF}=\mathrm{CF}_{2}$ ratio rather indeterminate.

When the kinetic chain length is much greater than the $\mathrm{C}_{n} \mathrm{~F}_{2 n-2} / \mathrm{CF}=\mathrm{CF}_{2}$ ratio, this ratio should be about equal to the ratio of cyclization to noncyclization, but when the kinetic chain length and the aforementioned ratio differ by a factor less than 10 , it is probable that an appreciable fraction of the observed double bonds may represent chain ends. These considerations give rise to the concept that the ratio of cyclization to noncyclization is about 20 for the octadiene, 200 for the hexadiene and a still larger but not precisely established value for the heptadiene. For each polymer, similar values of $\mathrm{C}_{n} \mathrm{~F}_{2 n-2} / C F=\mathrm{CF}_{2}$ were obtained under different polymerization conditions, suggesting that this ratio is not a strong function of either temperature or pressure.

Gelation occurs when a pendant vinyl group becomes incorporated in another chain, thus effecting a cross link between the two chains; thus, it may be used as a measure of the ratio of cyclization versus noncyclization. It is determined by extracting the polymer couple with boiling hexafluorobenzene and weighing both the soluble and insoluble fractions. The percent gelation is then determined by dividing the insoluble fraction by the weight of the total polymer sample. Polymer solution theory predicts that gelation will occur when the fraction of polymer formed is equal to the product of the ratio of cyclization to noncyclization and the reciprocal of the primary weight average degree of polymerization [18]. For cases where no gelation occurred a lower limit for the aforementioned ratio can be calculated by using $2 \dot{\gamma}$ as the weight average degree of polymerization and multiplying this value by the observed conversion. Cases in which gel formed may be used in the same way to compute an upper limit for the ratio. In this manner, $R$, the ratio of cyclization to noncyclization, has been computed for perfluoro-1,5-hexadiene, perfluoro-1,6-heptadiene, and perfluoro-1,7-octadiene. The values are $230<R$ $<10^{4}, 230<R$, and $6<R<320$, respectively.

In cases where the polymer yield is fairly low, an additional check is possible since in such cases $2 \gamma$ is a good estimate of the weight average degree of polymerization. For a most probable distribution the sol fraction may be used to compute the number of cross links per weight average molecule [19]. In this work computations of this sort tended to confirm values estimated through use of Beer's law computations.
Systematic studies with these monomers were hampered by sensitivity to impurities. The indicated results with perfluoro-1,7-octadiene were obtained with monomer which had not been purified on a prep scale vapor phase chromatograph. Polymer samples accordingly, gave values of $\gamma$ below those of other materials studied. Other samples in all cases were prepared from monomer which had been carefully chromatographed on a long column. The double bond migration which takes place so readily with perfluoro1.4-pentadiene [3] takes place less readily with the six, seven, and eight carbon fluorodienes. Whenever recovered monomer was used without chromatographic purification, lower rates were obtained. This diminution in rate was attributed to the presence of internal olefins resulting from double bond migration. Polymerization rates with pure monomer were about 200 to 500 times those obtained with perfluoro-1heptene in the same conditions [20]. It is uncertain whether this is due to a difference in monomer rate constants, difference in monomer purity, or to some effect of gelation on rate where dienes are concerned.

Attempts were made to avoid gelation by polymerization in solvents such as perfluorocyclobutane. The intention here was to take advantage of the hypothesis that the cyclization rate should be independent of monomer concentration while propagation should be directly related to monomer concentration so that dilution should increase the ratio of cyclization to noncyclization. Calculations using spectra of these polymers gave values of $\mathrm{C}_{n} \mathrm{~F}_{2 n-2} / \mathrm{CF}=\mathrm{CF}_{2}$ of $10^{3}$ or more. These spectra also showed intense absorption attributable to acid fluorides and internal double bonds. This is not easily explained since such absorptions were not observed with polymers prepared in bulk from highly purified monomer. A comprehensive study of the polymerization of these materials will be the subject of another communication.

\section{References}

[1] Fearn. J. E., and Wall. L. A., SPE Trans. 3, 231 (1963).

[2] Fearn, J. E., Brown, D. W., and Wall, L. A., J. Polymer Sci. 4 Part A, 131-140 (1966).

[3] Brown. D. W., Fearn. J. E., and Lowry, R. E., J. Polymer Sci. 3 Part A, 164l-1660 (1965).

[4] Park, J. D., and Lacher, J. R., W.A.D.C. Tech. Report 56-590, Part 1. 21-22 (1957).

[5] Butler, G. B., and Agnello, R. J., J. Am. Chem. Soc. 79, 3128 (1957).

[6] Miller, W. T., private communication.

[7] Hauptschein, M., and Fainberg. A. H., J. Am. Chem. Soc. 83, 2495 (1961).

[8] Knunyants. I. L., Chai-yuan. Li, and Shokina. V. V., Doblady. Akad. Nauk. SSSR 136, 610-12 (1961).

[9] Haszeldine, R. N., J. Chem. Soc. 4291-4305 (1955).

[10] Knunyants. I. L., Chai-yuan, Li, and Shokina, V. V.. Izvestia Akad. Nauk. SSSR, Otdelenie Khimicheskikh Nauk. 10, 1462-68 (1961).

[11] Knunyants, I. L., Chai-yuan, Li, and Shokina, V. V., Izvestia Akad. Nauk. SSSR, Otdelenie Khimicheskikh Nauk 10. 1910-11 (1961).

[12] Miller, William T., U.S. Patent 2,668,182 (1954).

[13] Hauptschein. M., and Braid, M.. J. Am. Chem. Soc. 83, 2500 (1961). 
[14] Knunyants, I. L.. Khrlakyan. S. P., Zeifman, Yu. V., and Shokina, V. V., Doklady. Akad. Nauk. SSSR 2, 384 (1964).

[15] Hauptschein, M., Braid, M., and Lawlor, F. E., J. Am. Chem. Soc. 79, 2549 (1957).

[16] Brown. D. W., private communication.

[17] Wall. L. A., Brown. D. W., and Florin. R. E., Am. Chem. Soc. Polymer Preprints 4, No. 2. 366 (Sept. 1961).
[18] Flory. P. J., Principles of Polymer Chemistry (Cornell Univ. Press. 1953) p. 391.

[19] Charlesby, A., Atomic Radiation and Polymers (Pergamon Press, 1960) p. 145.

[20] Brown. D. W., and Wall. L. A., SPE Trans. 3, 300 (1963).

(Paper 75A1-649) 